\title{
Toughness characterization and toughening mechanisms
}

\section{S.P. SHAH}

Northwestern University, Evanston, Mlinois, USA

A.M. BRANDT

Polish Academy of Sciences, Warsaw, Poland

C. OUYANG

Iowa Department of Transportation, Ames, Iowa, USA

R. BAGGOTT

University of Salford, Salford, United Kingdom

J. EIBL

University of Karlsruhe, Karsruhe, Germany

M.A. GLINICKI

Polish Academy of Sciences, Warsaw, Poland

H. KRENCHEL

Technical University of Denmark, Lyngby, Denmark

A. LAMBRECHTS

Bekaert n.v., B-Zwevegem, Belgium

V.C. LI

University of Michigan, Ann Arbor, Michigan, USA

B. MOBASHER

Arizona State University, Tempe, Arizona, USA

L. TAERWE

University of Ghent, Ghent, Belgium

\begin{abstract}
This chapter summarizes some state-of-the-art basic understanding on fiber reinforced concrete. Toughening mechanisms in fiber reinforced cementitious composites have been summarized based on several experimental observations. Some important experimental findings and interesting aspects of toughening mechanisms are presented. The effect of fiber on hindering the strain localization primarily depends on factors such as the fiber-matrix interface as well as volume, length and orientation of fibers. A series of theoretical models for describing these factors have been briefly discussed. Some current methods for characterizing toughness of fiber reinforced cementitious composites have been reviewed.
\end{abstract}

Keywords: debonding, fiber-matrix interface, processing technique, pullout of fiber, strain localization, toughening mechanisms, toughness. 


\section{Contents}

$1 \quad$ Fracture process in cementitious materials 194

2 Toughening mechanisms in fiber reinforced composites 195

3 Characterization of interfacial behavior $\quad 199$

3.1 Pullout of an aligned fiber

3.2 Pullout of an inclined fiber

3.3 Fracture of fibers

4 Characterization of composite behavior

4.1 Fracture mechanics approach

4.2 Micromechanics approach

5 Measurement of composite toughness

5.1 ASTM C 1018 method and its limitations

5.2 Methods based on fracture mechanics

6 Influence of processing technique

7 Design compressive strain softening curve 220

8 The effect of loading rate $\quad 221$

9 Summary 221

10 References $\quad 224$

\section{Fracture Process in Cementitious Materials}

Since concrete is a tension-weak material, failure of a concrete structure is usually governed by propagation of tensile cracks. Based on the propagation of cracks, a tensile stress-displacement relationship for a concrete specimen can usually be divided into four stages as shown in Fig. 1. The first stage is before point $A$ which is about $30 \%$ of the peak load. Initiation of internal cracks is negligible during the first stage. The second stage is from point $A$ to point $B$ which is about $80 \%$ of the peak load. The internal cracks initiate and propagate during this stage. But these cracks are isolated and randomly distributed over the specimen volume during the second stage. The third stage is between point $B$ and point $C$. The internal cracks start to localize into a major crack which propagates with increasing load [1][2]. This phenomenon is referred to as damage localization or strain localization. The crack length at the peak load is referred to as the critical crack length. The fourth stage is after the peak load. The major crack continuously propagates even though the load decreases. Mechanical response of a concrete structure is usually characterized by the peak load (strength) and toughness which is defined as the area distinguished. One needs to increase both the peak load and the toughness to obtain high material performance. This can be achieved by incorporating suitable amount and type of fibers into cement-based materials. A review on mechanical behavior of fiber-reinforced cement based composites has been given by Shah and Ouyang [3]. This chapter attempts primarily to summarize the recent development in this field. 


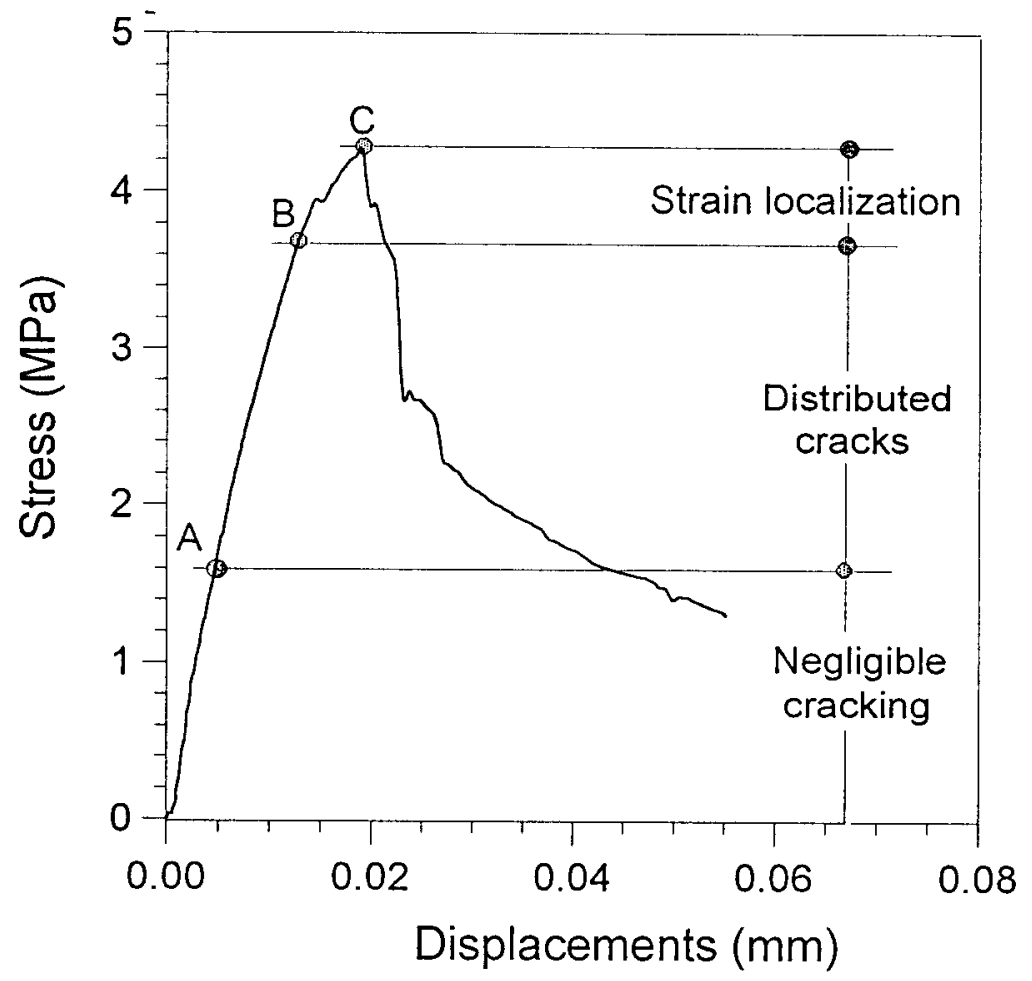

Fig. 1 Stress-displacement relationships and different cracking stages[1]

\section{Toughening mechanisms in fiber reinforced composites}

When some amount of microfibers are incorporated into a cement-based matrix, they can bridge microcracks and hinder them to form the microcrack band during stage BC (see Fig. 1). This can increase the peak load of the material. On the other hand, if relatively long and large diameter fibers are used as reinforcement, one may only observe small improvements in the peak load. However, once the microcracks coalesce into macrocracks, the long fibers provide bridging stress across the crack, and this bridging stress may arrest further propagation of the macrocracks. As a result, the toughness of the material can increase. The influence of various fibers on performance of cement-based materials is illustrated in Fig. 2. As a result, by combining fibers of varying sizes into the cementitious matrix, improvements in both the peak stress and the post-peak toughening may be expected[4]. 


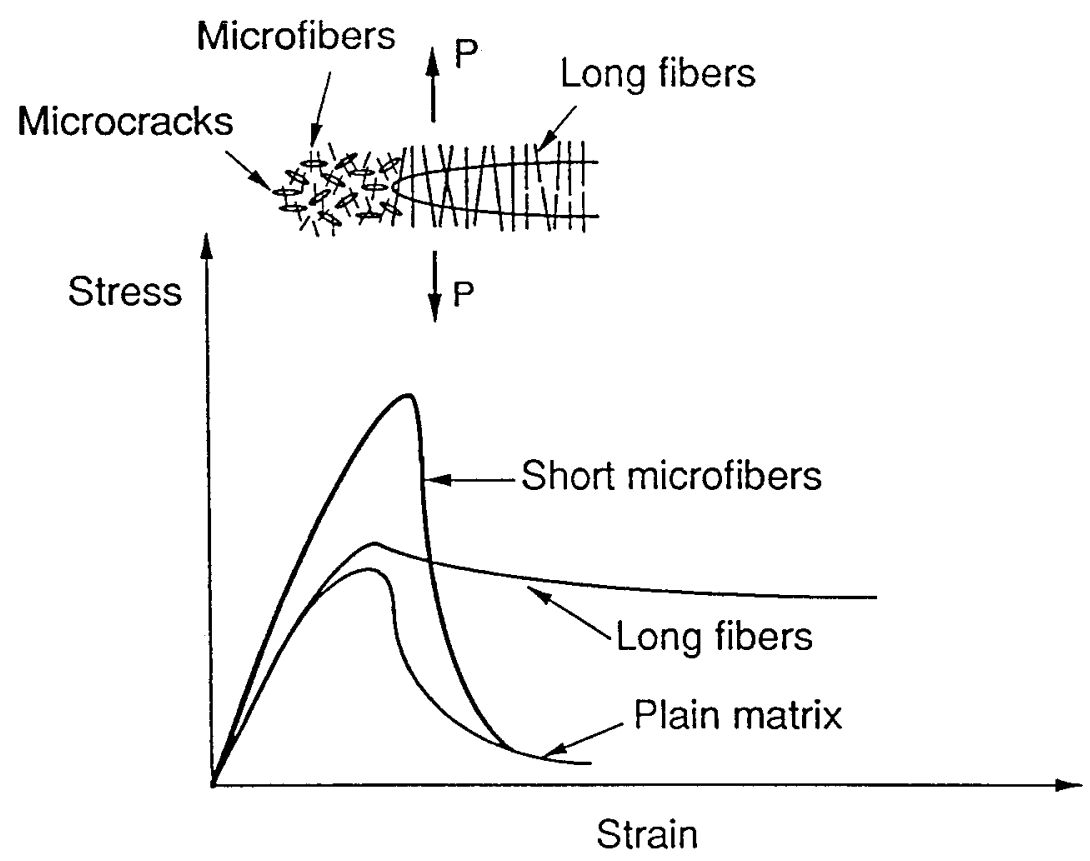

Fig. 2 Illustration of different sizes of fibers on crack bridging[4]

Many experimental studies, which include quantitative optical microscopy[5], laser holographic interferometry[6], acoustic emission[7] and moire interferometry [8] have been conducted to understand toughening mechanisms of fiber reinforced cement-based composites. A typical debonding and sliding process in a fiber reinforced cementitious composite is illustrated in Fig. 3, which was obtained by Shao et al. [8] using moire interferometry for a cement-based composite with $1.3 \%$ continuous steel fiber of $0.4 \mathrm{~mm}$ diameter. The stress-strain curve of the composite is also shown in the figure. Figs. $3 \mathrm{a}$ and $\mathrm{b}$ represents cracking at points $a$ and $b$ (see the stress-strain curve) recorded using the moire interferometry, respectively. The left crack in Figs. $3 a$ and $b$ was the first transverse matrix crack and the right one was the crack appeared thereafter. It was apparent that debonding had been initiated during matrix cracking. Interface debonding is characterized by the fringe discontinuity at the interface. At the center of the element, however, fringes were continuously passing through the fiber. Thus a part of the interface was still intact even at the end of multiple cracking (point a). With the increase of the load, debonding continued to propagate from both sides of the transverse matrix cracks. A small bonded area was again seen when the composite was loaded to a strain of about $0.28 \%$ (point $b$ ). 


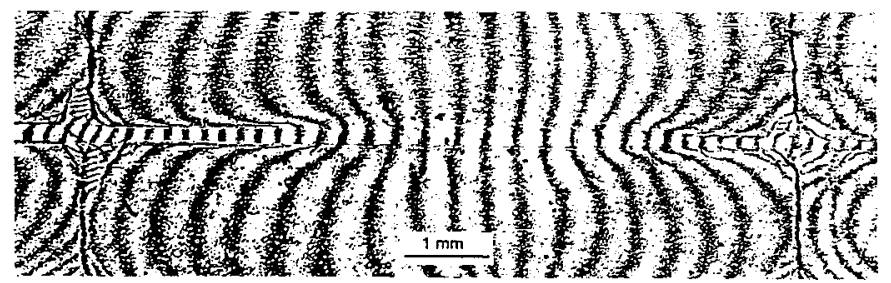

(a) Stress $=5.3 \mathrm{MPa}$

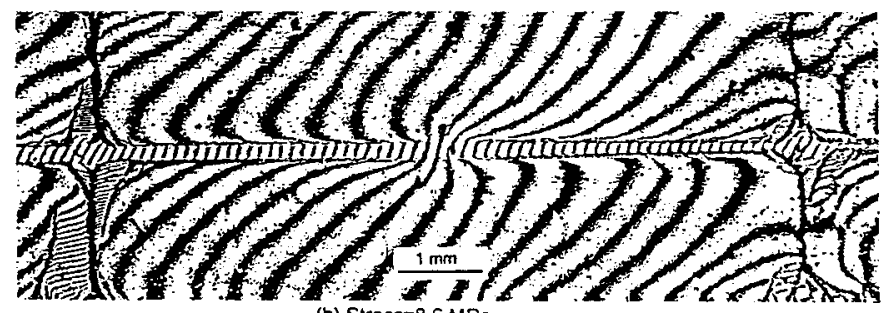

(b) Stress $=8.6 \mathrm{MPa}$
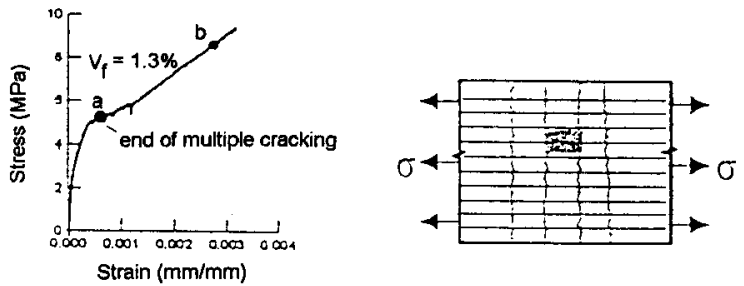

Fig. 3 Interface debonding and sliding for a cementitious matrix reinforced by $1.3 \%$ continuous steel fiber[8]

$\mathrm{Li}[9][10][11]$ recently tested a cementitious composite containing $2 \%$ by volume of randomly oriented discontinuous high modulus polyethylene fibers using a double cantilever notch beam. He found that advance of a main crack from the initial notch was significantly delayed and can only be observed after an extensive damage zone off the main crack plane has been developed. Inelastic energy absorption off the main crack plane was a new source of toughness. The crack pattern at the failure of the specimen is shown in Fig. 4a. He reported that the notch tip was rapidly blunted by the damage process and this blunting relaxes the strain-concentration, allowing further loading to be applied before the real crack growth can begin. This can leads to notch-insensitive cementitious composites as shown in Fig. $4 \mathrm{~b}$.

As a result, toughening of fibers in a cement-based material may be illustrated in Fig. 5. Fibers usually bridge a transverse matrix crack, and hinder propagation of the crack. The effect of fibers can normally be represented by a bridging force. Since some debonding and sliding generally occur on the interface between the fiber and the cementitious matrix, distribution and magnitude of the bridging force depend on the debonding and sliding response. To characterize behavior of fiber reinforced composites, one needs first to understand the interfacial response of the composites. 


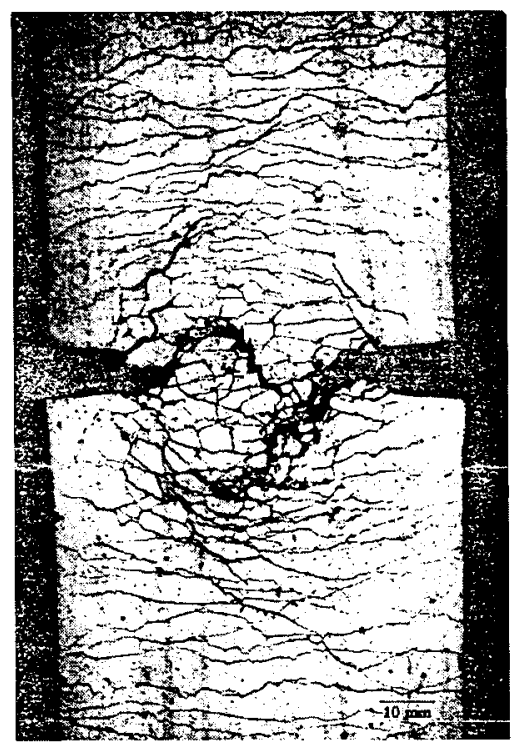

(a) Damage pattern of a double-edged-notched specimen

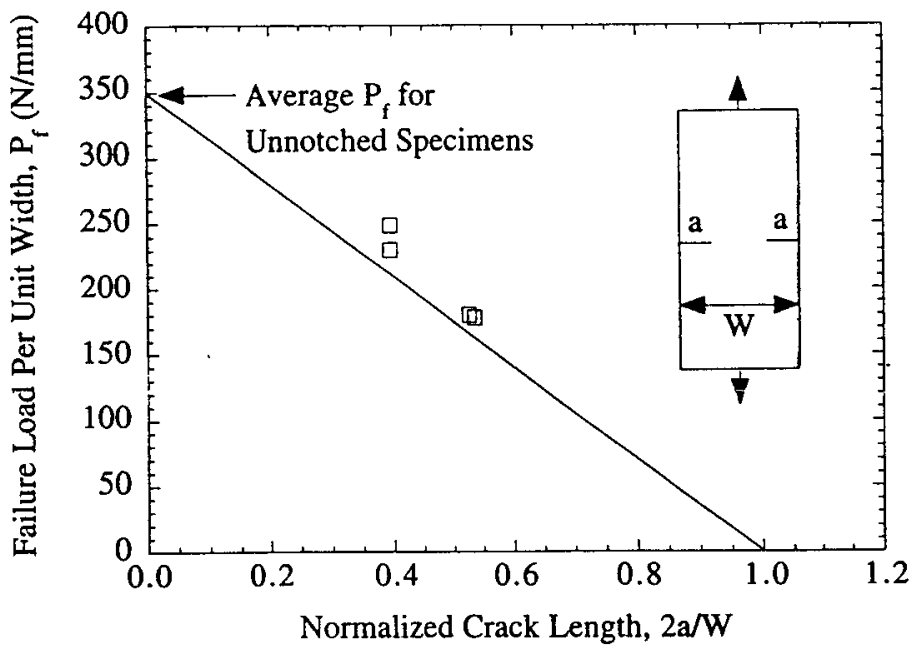

(b) Failure load versus notch depth

Fig. 4 A notch-insensitivity fiber-reinforced cement composite [9] 
$\sigma$

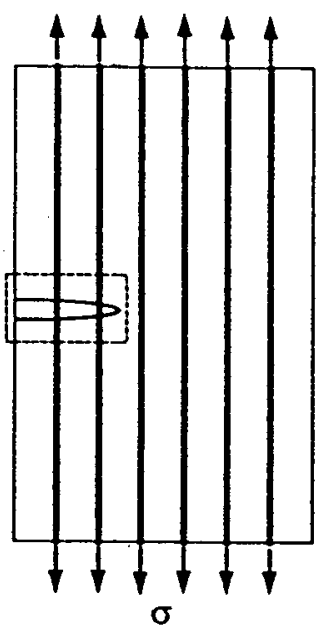

(a) Overall View of Specimen

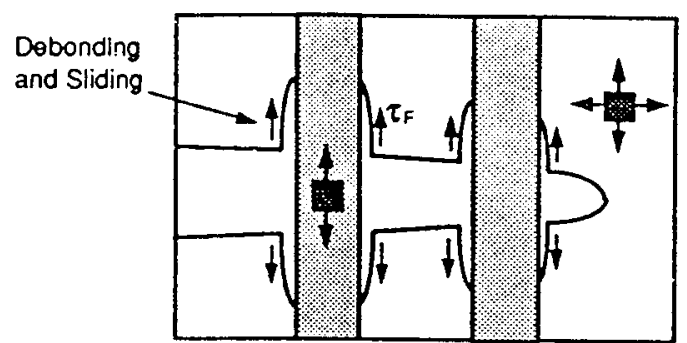

(b) Debonding and Sliding Associated with a Crack

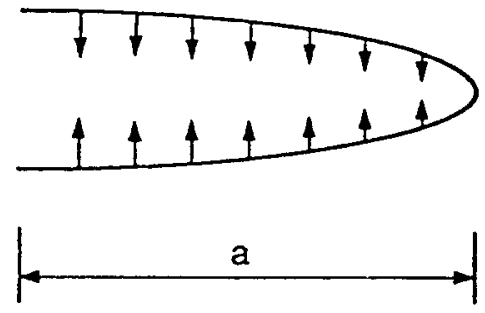

(c) Closing Pressure Used to Stimulate Effect of Fibers

Fig. 5 Toughening of fiber in a cementitious composite

\section{Characterization of interfacial behavior}

\subsection{Pullout of an aligned fiber}

Pull-out of a fiber from a cement-based matrix has been used to characterize the interface bond between the matrix and the fiber as shown in Fig. 6. Typical pull-out force and slip curves for a single fiber, average of 16 fibers being simultaneously pulled out at different inclination angles, are shown in Fig. 7. The pull-out load 


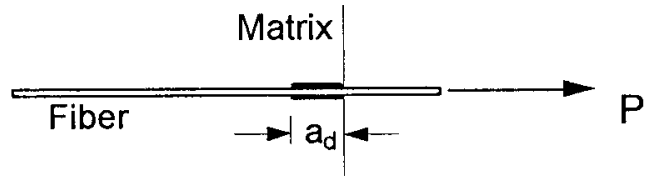

Fig. 6 Pullout of a fiber from a matrix

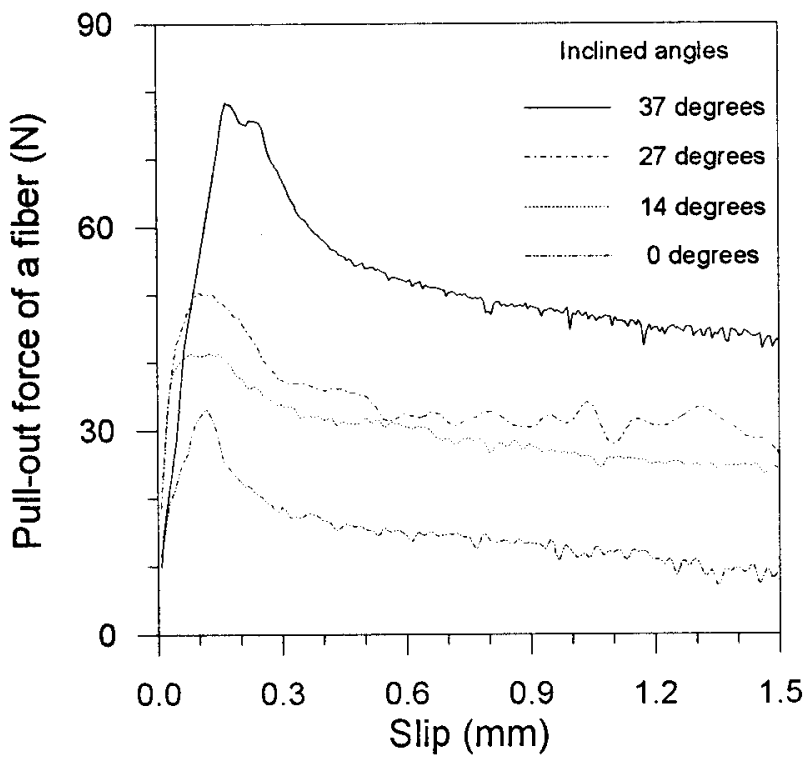

Fig. 7 Pullout force vs. slip curves for fibers with different inclinations[17] 
initially almost linearly increases with the slip. Nonlinearity in the pull-out load and slip curves, which is often regarded as an indication of propagation of an interfacial crack, is usually observed before the peak load[12]. After the pull-out load reaches the maximum value it decreases slowly with increasing slip. This result may indicate that when fibers are pulled-out from a cementitious matrix, an interfacial crack initiates at some point before the peak. This interfacial crack stably propagates up to peak load, i. e. the crack propagates only when the pull-out load increases. The interfacial crack length corresponding to the peak load is usually termed as the critical crack length. After the peak load, unstable crack growth occurs, which means that the crack automatically grows even though the pull-out load decreases. As a result, softening type load-slip curves are observed from the pull-out test.

To quantify results of pull-out test of fibers, it was initially assumed that shear stresses are uniformly distributed. The average shear strength, which is equal to the maximum pull-out load divided by the debonded surface area of the fiber, was initially used to characterize the interface response[13]. However, experimental results[14] have indicated that this average shear strength depends on embedded length and diameter of fibers.

To better characterize fiber-matrix interface behavior, a shear-lag approach[15][16] has been used to analyze stress and strain distributions in the interface. Stang et al.[17] proposed a shear-lag model which takes the effect of the weak zone between the fiber and the cement-based matrix. Based on the stress distributions obtained from a shear-lag analysis, they evaluated the strain energy release rate for pullout of fibers $G_{d}$ as,

$$
G_{d}=\frac{\left(P-\tau a_{d}\right)^{2} \operatorname{coth}^{2}\left[\omega\left(L-a_{d}\right)\right]}{4 E_{f} \pi^{2} r^{3}}-\frac{\tau\left(P-\tau a_{d}\right)}{2 E_{f} \pi^{2} r^{3} \omega} \operatorname{coth}\left[\omega\left(L-a_{d}\right)\right]+\frac{\tau}{4 \pi r k}
$$

where $P$ is the pull-out load of the fiber, $\tau$ is the frictional stress between the fiber and the matrix, $a_{d}$ is the debonded length at fiber-matrix interface, $\mathrm{L}$ is the fiber embedded length, $r$ is the fiber radius, $E_{f}$ is the modulus of elasticity of the fiber, $k$ is the initial slope between the shear stress and the slip, and $\omega$ is a parameter to quantify stiffness of weak interface layer between the fiber and the matrix and is defined as:

$$
\omega=\sqrt{\frac{k}{E_{f} \pi r^{2}}}
$$

By introducing a linear elastic fracture mechanics (LEFM) Griffith type debonding criterion, $\mathrm{Li}$ et al.[18] have used $\mathrm{Eq}$. (1) to evaluate interfacial parameters based on their experimental results. They reported that the value of $\omega$ is basically independent of the fiber embedded length, $L$. However, the value of the critical debonding energy obtained depends on $L$. Then a question raised is whether or not the $L E F M$ criterion is suitable for describing debonding between the fiber and the matrix. When a fiber is pulled out from a matrix, the interface between the fiber 
and the matrix first debonds. Then some slip occurs due to a relative movement between the fiber and the matrix. Since the debonded length at the peak load is smaller than $L$ during this stage, the slip prior to the peak load may be relatively small and the effect of the frictional stress on the pull-out behavior may be neglected during this stage. As a result, if only the peak pullout load is concerned, Eq. (1) can be simplified as $(\tau=0)$

$$
G_{d}=\frac{P^{2} \operatorname{coth}^{2}\left[\omega\left(L-a_{d}\right)\right]}{4 E_{f} \pi^{2} r^{3}}
$$

The substantial pre-peak non-linearity as seen in Fig. 7 indicates the fact that stable propagation of the debonding crack must exist before the peak load. Ouyang et al. [19] have used the following fracture resistance curve $\left(\mathbf{R}_{d}\right.$-curve) to describe this stable debonding process,

$$
\begin{aligned}
& R_{d}=\beta\left(a_{d}-a_{d 0}\right)^{d} \\
& d=\frac{1}{2}+\frac{\alpha-1}{\alpha}-\left[\frac{1}{4}+\frac{\alpha-1}{\alpha}-\left(\frac{\alpha-1}{\alpha}\right)^{2}\right]^{1 / 2}
\end{aligned}
$$

where $R_{d}$ is the fracture resistance, and $\alpha$ and $\beta$ are constants to be determined. To determine the parameters $\alpha$ and $\beta$, one needs to test a reference specimen with the embedded fiber length of $L_{f}^{*}$ to obtain its maximum pull-out load, $P_{c}^{*}$. Values of $\alpha$ and $\beta$ can then be determined using this reference value of $P_{c}{ }^{*}$ and the interface parameter $\omega$. The energy balance during the pullout process requires $R_{d}=G_{d}$, and this leads to

$$
P=\left\{\frac{4 E_{f} \pi^{2} r^{3} \beta\left(a_{d}-a_{d 0}\right)^{d}}{\operatorname{coth}^{2}\left[\omega\left(L-a_{d}\right)\right]}\right\}^{1 / 2}
$$

For a fiber with given radius and embedded length, the relationship between the pullout load, $P$ (up to the peak), and the debonding length, $a_{d}$, can be calculated using Eq. (5), where the peak pullout load corresponds to the maximum value of $P$. For a series of fibers with the same radius but different embedded lengths, L, the peak pullout load can also be predicted from Eq. (5) as shown in Fig. 8, where the experimental results reported by Somayaji and Shah [20] are compared with the theoretical prediction.

\subsection{Pullout of an inclined fiber}

When a fiber is pulled out from a matrix at an inclined angle of $\theta$ as shown in Fig. 9, the pull-out load, $P_{\theta}$, can be divided into two components, $P_{x}$ and $P_{y}$. When the value of $\theta$ is small than $45^{\circ}$, pull-out resistance of inclined fibers is usually higher than that of aligned fibers. This is first due to the fact that only a component in the 


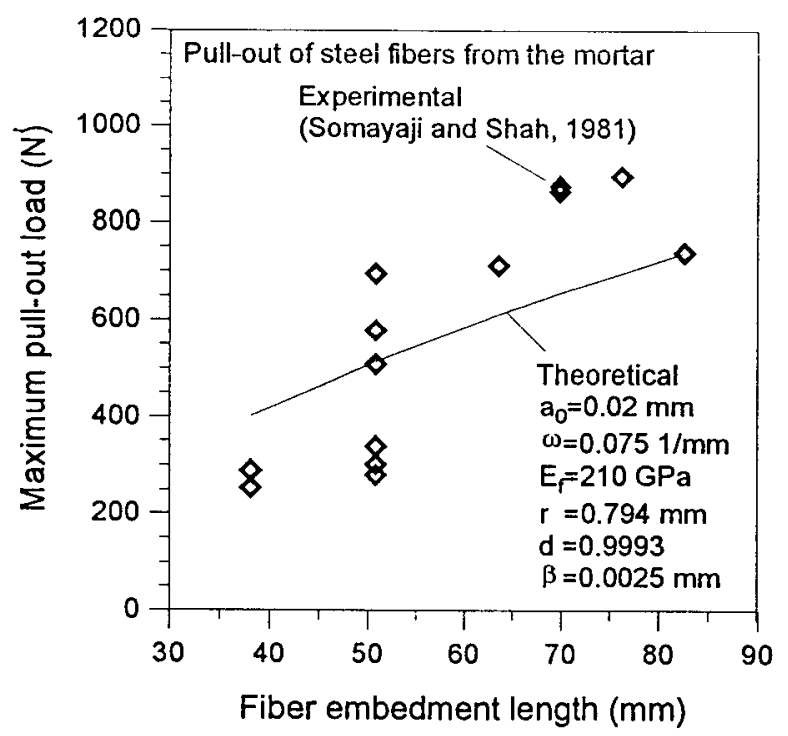

Fig. 8 Comparison of predicted and experimental maximum pullout loads[19]

fiber axis, $P_{x}$, is dedicated to pull-out the fiber. This may be referred to as the pulley effect. There are several models proposed to explain the role of the other component, $\boldsymbol{P}_{y}$. For pull-out of inclined metal fibers from a matrix, Morton and Groves[21] proposed that both bending of the fiber at its exit from the matrix and spalling of the matrix are major mechanisms to account for this increase. This is termed as the bending mechanism. On the other hand, Brandt[22] considered that fiber yielding and matrix spalling at the fiber exit point from the matrix should be responsible for this increase of pull-out resistance. This is referred to as the yielding mechanism. For pull-out of inclined synthetic fibers, $\mathrm{Li}$ et al.[23] reported that the increase of pull-out resistance is due to an additional friction stress generated.

The pulley effect always exists for pull-out of all types of inclined fibers. The question needed to be answered is what kind of mechanism is most suitable to explain the role of the component $\boldsymbol{P}_{\boldsymbol{y}}$ in pull-out of metal fibers from a cementitious matrix. Both the bending mechanism and the increase of frictional stress may exist during fiber pull-out. Since the fiber will almost immediately be bent when a pullout force starts to apply, the bending mechanism is present even though the pull-out load is small. On the other hand, frictional stress at the fiber-matrix interface will be generated only when the fiber and the matrix start to slip (the interface first debonds then the fiber and the matrix slip). Since the slip value prior to the peak pullout load is relatively small, the effect of frictional stress on pull-out of inclined metal fibers may not be dominant before the peak load. Therefore, both the pulley effect and the bending mechanism may primarily account for increase of peak pullout load for inclined fibers. However, the influence of frictional stress become more 


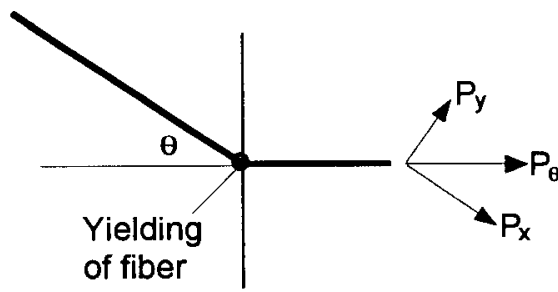

Fig. 9 Pullout of an inclined fiber from a matrix

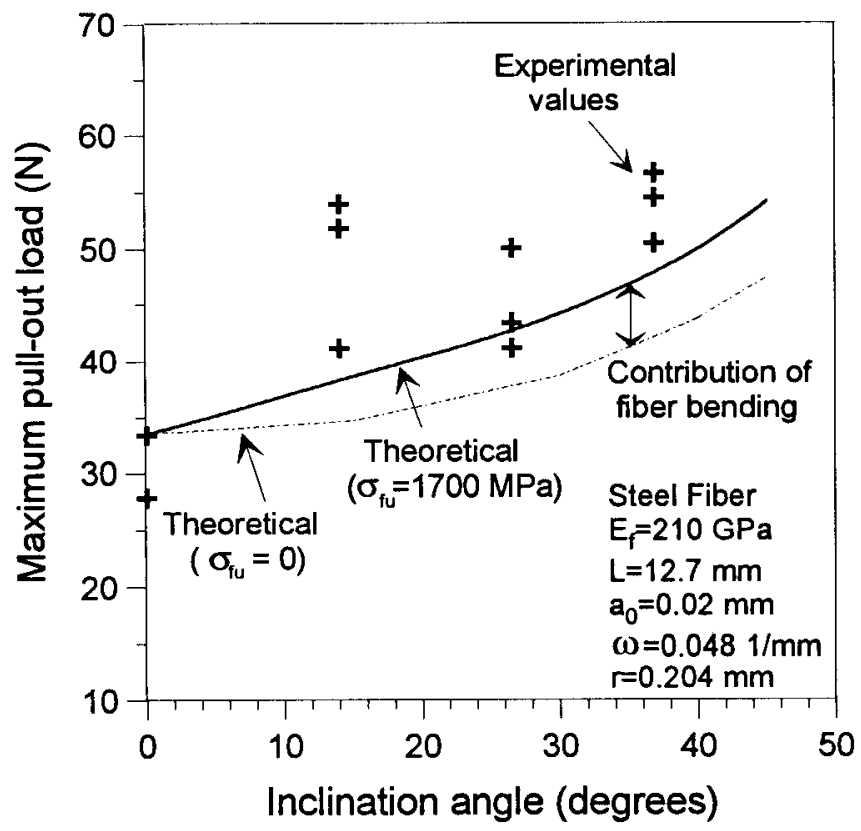

Fig. 10 Experimental and theoretical comparison of maximum pull-out load for steel fibers[19] 
and more important after the peak load because more slipping occurs. Based on this discussion, Ouyang et al. [19] have extended their approach to predict the peak pullout load of inclined fibers by taking the bending energy into account. They obtained the peak pullout load of an inclined fiber as

$$
\begin{aligned}
& \frac{P_{\theta}^{2} \cos ^{2} \theta \operatorname{coth}^{2}\left[\omega\left(L-a_{d}\right)\right]}{4 \pi^{2} r^{3} E_{f}} \\
& -\frac{m P_{\theta} \cos \theta}{16 \pi r}\left(\frac{\sigma_{f y}}{E_{f}}\right)^{2}\left\{1+\frac{1}{\sinh ^{2}\left[\omega\left(L-a_{d}\right)\right]}\right\}-\beta\left(a_{d}-a_{d 0}\right)^{d_{2}}=0
\end{aligned}
$$

where $\sigma_{f y}$ is the yielding strength of the fiber, and $\mathrm{m}$ is a constant accounted for the length of fiber yielded. Since Eq. (6) includes the bending mechanism, it is valid only when the fiber is yielded. Eq. (6) may not apply to the case when a matrix wedge failure also occurs as the fiber is pulled-out. This usually occurs when $\theta_{i}>$ $45^{\circ}$.

The theoretical predictions are also compared to the experimental results of inclined steel fibers pulled-out from a cement paste. The steel fiber had a diameter of $0.408 \mathrm{~mm}$, and the embedment length of the fiber was $12.7 \mathrm{~mm}$. The value of $m \approx 20$ was used. The values of $a_{d 0}=0.02 \mathrm{~mm}$ and $\omega=0.0481 / \mathrm{mm}$ were used. The value of $P_{c}=33.5 \mathrm{~N}$ for the aligned fiber was used as the reference value for the theoretical prediction. Both the values of $\sigma_{f y}=1700 \mathrm{MPa}$ and $\sigma_{f y}=0$ were used for theoretical prediction. The value of $\sigma_{f y}=0$ corresponds to the case where the bending effect on fiber pullout load is negligible. As a result, the bending effect can be separated as shown in Fig. 10.

Pacios et al.[24] have extended the above model to predict the influence of loading rate on pullout behavior.

\subsection{Fracture of fibers}

When fibers are long enough, then part of fibers may break. This effect is rarely encountered in steel fiber reinforced cementitious composites but it usually occurs when carbon, glass or polymeric fibers with aspect ratio of greater than 100 are used. The fracture of fibers is confirmed by SEM images and by bending and tensile tests. For example, Park et al.[25] have shown that high strength pan carbon fibers are clearly more efficient than low strength pitch fibers. Similar results were obtained by Mihashi et al.[26] on other types of specimens and loading states. Possibility of fracture of fibers should be considered when toughening mechanisms are analyzed.

\section{Characterization of composite behavior}

\subsection{Fracture mechanics approach}

The presence of fibers provides an additional toughening on concrete. This is shown in Fig. 5. As previously mentioned, the influence of fibers can be modeled by a closing pressure on cracked surfaces. The closing pressure tends to close the crack. 
Based on the two parameter fracture model, Mobasher et al.[27] and Ouyang and Shah [28] have applied the $R$-curve given by Eq. (4) to predict the tensile stress at bend over point (BOP) for a cementitious matrix reinforced by fibers (now $R_{i n t}$ and $a_{d}$ should be replaced by $R$ and $a$, respectively). By using the principle of superposition, two failure criteria for concrete with fiber reinforcement become,

$$
K_{I c}^{s}=K_{I m}\left(\sigma_{m c}, a_{c}\right)-\int_{0}^{a_{c}} p\left(x, a_{c}\right) K_{F}\left(x, a_{c}\right) d x
$$

and

$$
C T O D_{c}=C T O D_{m}\left(\sigma_{m c}, a_{c}, a_{0}\right)-\int_{a_{0}}^{a_{c}} p\left(x, a_{c}\right) Q\left(\sigma_{m c}, a_{c}, a_{0}\right) d x
$$

where $\sigma_{m c}$ is the stress at the $B O P$ resisted by the matrix with fiber reinforcement, $Q$ is the Green's function for the crack closure at point $a_{0}$ (initial crack mouth) due to a unit force applied at point $x$ along the crack length, $p_{f}$ is the closure force at point $x$ along the crack face, and $K_{F}$ is the stress intensity due to a unit load applied at point $\mathrm{x}$ along the crack surface. The parameters $K_{I m}, C T O D_{m}, K_{F}$, and $Q$ can be obtained based on LEFM. Two unknowns, $\sigma_{m c}$ and $a_{c}$, can be solved from Eqs. (7) and (8). Then, the parameters $\alpha=a_{c} / a_{0}$ can be determined. The value of $\beta_{2}$ can be obtained from the condition of $R_{c}=\left(K_{I c}^{s}\right)^{2} / E=G_{c}$, where $G$ for the single edge notch tensile member should be used for $G_{c}$. After both $\alpha$ and $\beta$ are determined, the R-curve is known. The mechanical response of matrices reinforced by fibers can be predicted using $R=G$. It is noted that in the above analysis, one can use either the experimental pull-out slip curve as shown in Fig. 6 or the theoretical pullout slip curve as previously presented as the closing pressure.

Mobasher et al.[29][30] have proposed two methods, the modified LEFM method and the compliance method, for experimentally measuring R-curve of fiber reinforced cementitious composites. In the compliance method, the strain energy release rate $G^{*}(a)$, which includes the effect of residual displacement after unloading, is defined as

$$
G^{*}(a)=G(a)+\frac{P}{2 t} \frac{\partial \delta_{r}}{\partial a}
$$

where G(a) is the LEFM strain energy release rate which can be evaluated based on unloading compliance, $\mathrm{P}$ is the applied load, and $\delta_{\mathbf{r}}$ is the residual displacement which can be obtained from loading-unloading procedure. The fracture resistance $\mathrm{K}^{\mathrm{R}}(\mathrm{a})$ can then be obtained for the plane stress condition

$$
K^{R}(a)=\sqrt{E_{c} G^{*}(a)}
$$

where $E_{c}$ is the elastic modulus of the composites. 
A typical load-deflection curve experimentally obtained is shown in Fig. 11 for a cementitious mortar reinforced by $1 \%$ of alumina fiber[29]. Based on the unloading compliance and the residual displacement, values of $K^{R}(a)$ corresponding to each unloading can be evaluated using Eqs. (9) and (10). The such obtained $\mathbf{K}^{\mathbf{R}}$ (a) curve is shown in Fig. 12, where the result using the modified LEFM method is also given. Since the modified LEFM method neglects the effect of the residual deflection, it over-estimates the $K^{R}$ (a) values after the peak load.

\subsection{Micromechanics approach}

Yang et al.[31] developed a micromechanical inclusion method for simulating matrix toughening due to fiber reinforcement. They first calculated the stress distributions of fiber and matrix using the equivalent inclusion method. Then, the crack initiation was described by the Griffith fracture criterion. In their analysis, a crack in a brittle matrix was modeled by an ellipsoidal inclusion. By using their model, four possible fracture stages before the BOP, as shown in Fig. 13, can be predicted. Based on this model, the applied stress at crack initiation in the matrix corresponding to perfect bond of the interface (i. e. bridging only, see curve 1 in Fig. 13) is given by:

$$
\sigma_{a}=\left[\frac{\pi \mu_{c} G_{m c}}{2\left(1-v_{c}\right) a}\right]^{\frac{1}{2}}\left(1+\frac{2 a}{3 r} V_{f}\right)^{-\frac{1}{2}}\left(1+\frac{a}{r} V_{f}\right)
$$

where $\sigma_{\mathrm{a}}$ is the applied stress, $\mu_{\mathrm{c}}$ and $\nu_{\mathrm{c}}$ are the average shear modulus and Poisson's ratio of the composite, and a is the crack length. The crack propagates through the matrix despite bridging of fibers in the second stage. When the crack reaches a certain length, debonding and sliding occur at the fiber-matrix interface (stage three). The applied stress for the initiation of the debonding and the sliding is given by (curve 2 in Fig. 13):

$$
\sigma_{a}=\left(\frac{8 r G_{i} E_{f}}{2 a^{2}}\right)^{\frac{1}{2}}\left(1+\frac{a}{r} V_{f}\right)
$$

Debonding and sliding increase when the crack further propagates. By using similar energy balancing conditions, the asymptotic relation for steady state cracking $(a / r \rightarrow \infty)$ was obtained (curve 3 in Fig. 13). Yang et al. [29] further found that a critical fiber volume fraction, $V_{\mathrm{fc}}$, for debonding of the fiber-matrix interface at the BOP can be derived by equating Eqs. (9) and (10) for $\mathrm{a} / \mathrm{r} \rightarrow \infty$ :

$$
V_{f c}=\frac{3 \pi \mu_{c} G_{m c}}{16 E_{f}\left(1-v_{c}\right) G_{i}}
$$

If $V_{f}$ is less than $V_{f c}$, debonding between fiber and matrix occurs before the BOP, whereas if $V_{f}$ is greater than $V_{f c}$, no debonding occurs before the BOP. The value of $V_{f c}$ depends on fiber and matrix properties, but is independent of the fiber 


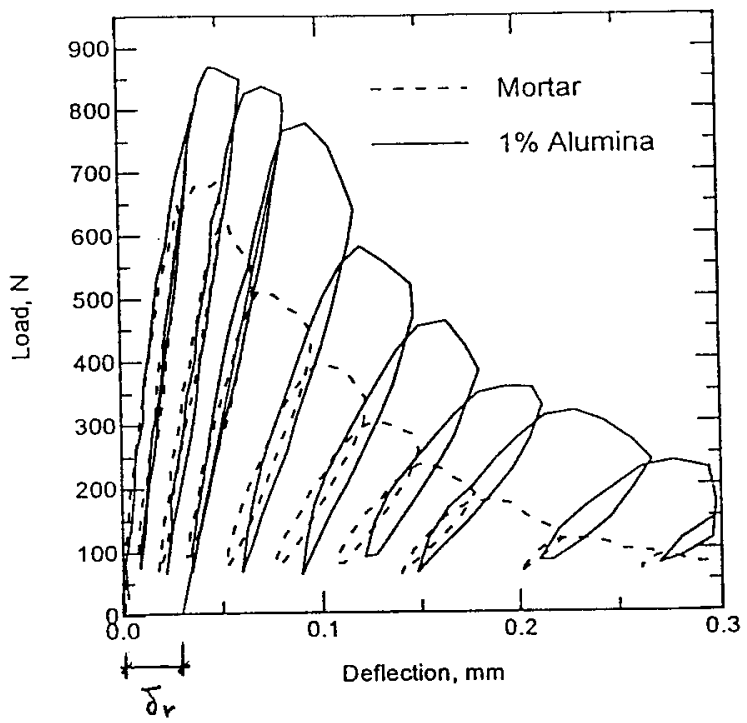

Fig. 11 Loading-unloading curves used for determining R-curves[29]

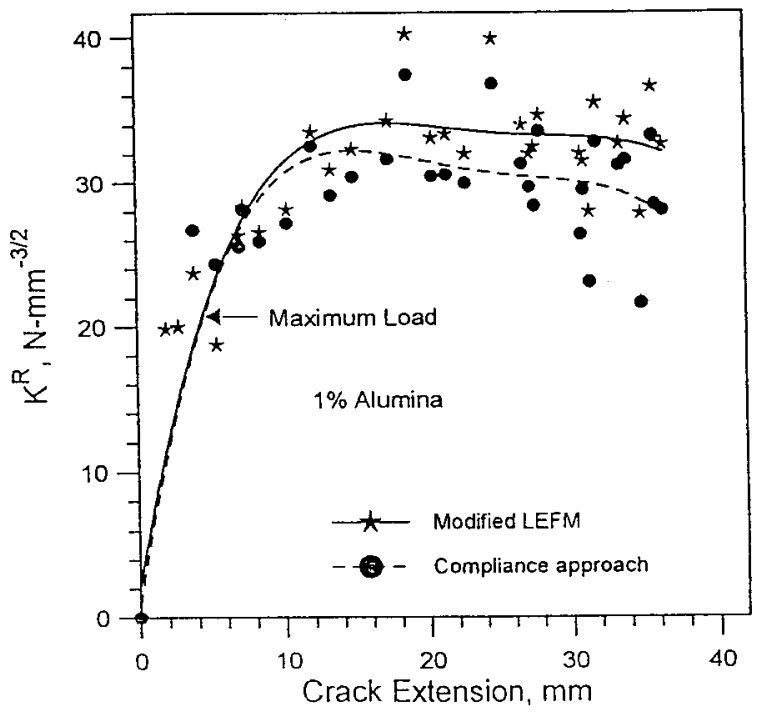

Fig. 12 Measured R-curves for a fiber-reinforced cementitious composite[29] 
(1) Bridging only (perfect bond)

(2) The initiation of debonding

(3) Maximum debonding and sliding

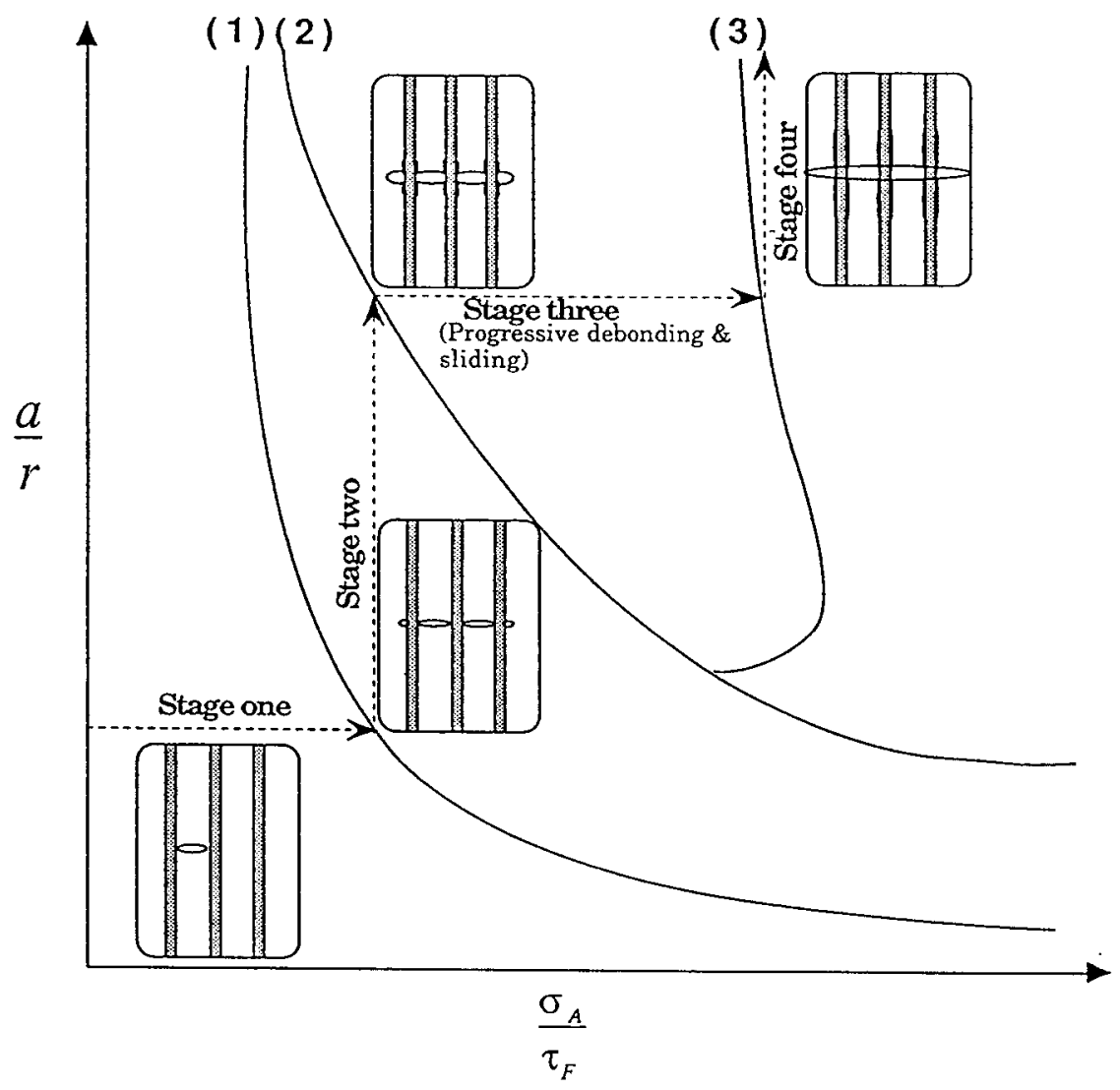

Fig. 13 Four cracking stages for fiber reinforced composites[31]

radius. To more efficiently use fibers, one may design cement-based composites with $\mathrm{V}_{\mathrm{f}}<\mathrm{V}_{\mathrm{fc}}$.

$\mathrm{Li}$ et al. [32] further extended this inclusion method to predict multiple cracking of fiber reinforced composites.

Brandt[20] studied the optimal direction of short metal fibers in composites by performing a micromechanical analysis. He respectively evaluated various components of the fracture energy resulting from (i) debonding on the interface between matrix and fibers, (ii) pulling of debonded fibers out of the matrix, (iii) plastic deformation of metallic fibers when they pass across a transverse crack, (iv) 
crushing of the matrix at exit point of fibers passing the transverse crack, and (v) additional friction between the fibers and the matrix due to local compression. The total energy, which is the function of fiber inclination angle, is the sum of these energy components. The optimal inclination angle was then obtained by maximizing this total energy. Based on properties of matrix and fibers, this optimal angle for most conventional composites may vary from 10 to 40 degrees. Brandt and Stroeven[33] further performed a test on four-point bending beams made of steel fiber reinforced concrete for measuring the fracture energy. They reported that theoretically calculated and experimentally measured fracture energies were quite agreeable.

\section{Measurement of composite toughness}

In most engineering applications, only up to about $1 \%$ of fibers by volume was incorporated in cementitious materials. With this low volume ratio of fibers, fibers only increase toughness of the materials. Toughness is defined as the area under a load-deflection curve here. Therefore, how to measure toughness for composites with low fiber volume ratio is very important for engineering applications.

\subsection{ASTM C 1018 method and its limitations}

Two types of toughness are currently used to characterize fracture behavior of fiber reinforced concrete. ASTM C 1018[34] uses toughness indexes $I_{5}, I_{10}$ and $I_{30}$ to characterize fiber reinforced concrete. These indexes are calculated as ratios of the area of the load-deflection curve up to 3, 5.5 and 15.5 times the first-crack deflection divided by the area of the load-deflection curve up to the first-crack deflection, respectively. On the other hand, JCI SF4[35] has introduced an absolute toughness $T_{\mathrm{JCI}}$ which is defined as the energy required to deflect the fiber reinforced concrete beam to a midpoint-deflection of $1 / 150$ of its span. Gopalaratnam et al.[36] have conducted a round-robin test on measuring the toughness of fiber reinforced concrete beams. The influence of fiber volume fraction, beam size and fiber type on the toughness measurement was experimentally studied. The obtained load-deflection curves were characterized by ASTM C 1018, JCI SF4 and ACI 544[37], respectively. They observed that ASTM C1018 toughness indexes are greatly affected by errors in measuring the first-crack deflection. These errors include (a) elastic and inelastic deformations due to local deformation and crushing of the specimen at the loading points, (b) elastic and inelastic deformations of the loading fixture, and (c) deflection due to specimen rocking. They reported that the ASTM C 1018 toughness indexes were observed to be relatively insensitive to fiber type, fiver volume fraction and specimen size. They also found that toughness as a measure of absolute energy, like $T_{\mathrm{JCI}}$, is capable of distinguishing among composites with different fiber types, different fiber volume fractions and different specimen sizes. Mindess et al.[38] conducted a study on measuring the first crack strength and flexural toughness of steel fiber reinforced concrete, and a similar conclusion was reached by them.

Lambrechts[39] has recently tested a series of beams made of fiber reinforced high strength concrete. The obtained load-deflection curves were used to calculate the toughness based on ASTM C1018 and JCI SF4, respectively. He 
reported that since high strength concrete is more brittle than normal strength concrete, the former exhibits more significant strain softening behavior than the latter. As a result, the ASTM C1018 toughness indexes obtained for fiber reinforced high strength concrete become very unreliable. He also observed breakage of some the normal strength hooked-end steel fibers in the high strength concrete at post-peak loading stage. As a result, he recommended the use of high strength hooked-end steel fiber in high strength concrete in order to achieve great ductility.

Limitations of the ASTM C1018 toughness indexes can be further demonstrated by load-deflection curves given in Fig. 14[40][41]. Curves $a$ and $a$ ' have different shapes, but they have the same value of $I_{5}=3$ based on ASTM C1018. Similarly, curves $b$ and $b^{\prime}$, and curves $c$ and $c^{\prime}$ have the same values of $I_{10}$ and $I_{20}$, respectively. This indicates that ASTM C1018 cannot uniquely characterize fracture property of fiber reinforced concrete.

Kucharska and Brandt[42] recently conducted a series of tests on pitch-based carbon fiber reinforced cement mortars. They obtained considerable increase of fracture toughness expressed by the indexes $\mathrm{I}_{5}, \mathrm{I}_{10}$ and $\mathrm{I}_{20}$, while the improvement of bending strength (MOR) was quite negligible. They concluded that the toughness indexes are useful if applied with caution and together with other toughness measures like energy absorbed up to peak load and/or up to zero load.

Glinicki[43] has studied energy absorption of glass fiber reinforced cement (GFRC) composite. Because the GFRC composite is usually manufactured in the form of thin plates, conventional methods using beams may not apply to the GFRC composite. Therefore, his study included an experimental evaluation of GFRC energy absorption capacity using both beam and plate specimens, respectively. Both

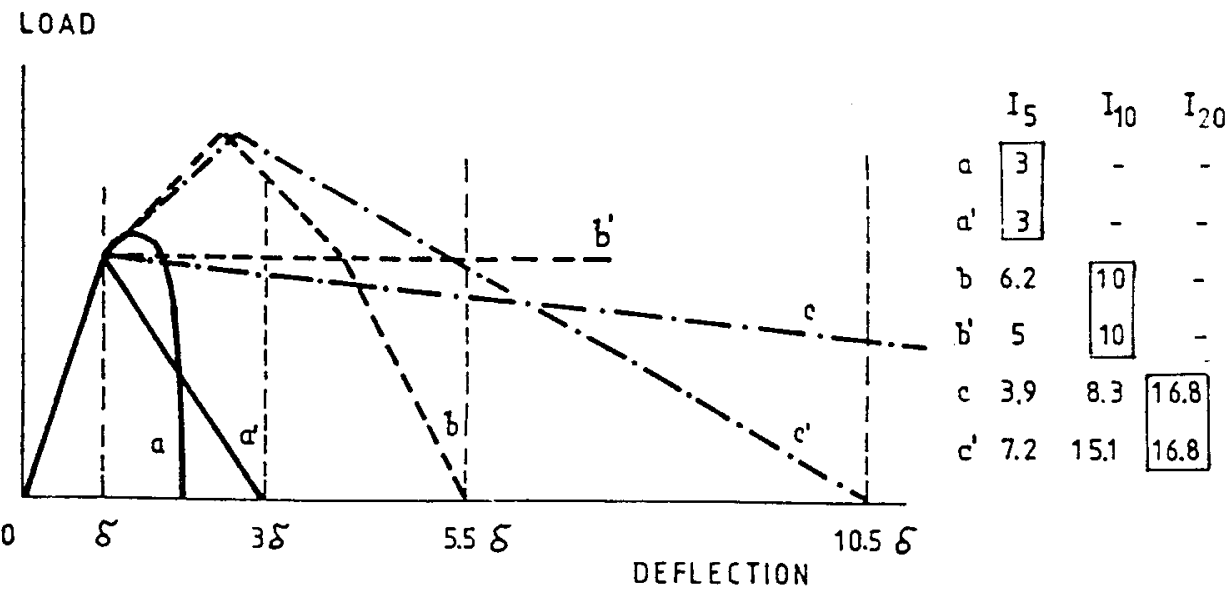

Fig. 14 Illustration of non unique toughness indexes based on ASTM C 1018[40] 
polymer modified glass fiber reinforced cement (P-GFRC) and metakaolin and polymer modified glass fiber reinforced cement (MP-GFRC) were tested. Based on the experimental results obtained, Glinicki reported that load-displacement curves measured using two types of specimens, respectively, doesn't result in a clear correlation of beam and plate behavior, but some observations are consistent, e.g. a ratio of the strain hardening regime to the first-crack regime is similar for both the beam and plate specimens. He also reported that the MP-GFRC composite has a better toughness characteristics than the P-GFRC composite. The former has 1.3 times of the average maximum bending compared to the latter for both beam and plate specimens. The former also demonstrates a better long term energy absorption capacity than the latter.

\subsection{Methods based on fracture mechanics}

Since ASTM C1018 cannot properly characterize fracturc behavior of fiber reinforced concrete, many other methods have recently been proposed. Among those, methods based on concepts of fracture mechanics may be most promising, Gopalaratnam et al.[36] proposed the use of notched beams for load-CMOD (ciack mouth opening displacement) measurement as shown in Fig. 15, instead of loaddeflection curve. The CMOD measurement automatically exclude almost all extraneous sources of deformations typically associated with the deflection measurement. Thus, the former is expected to provide more representative data from the specimens than the latter. This is illustrated in Fig. 16(a) and (b) for different fiber volume fraction[36]. The other advantages of using load-CMOD response to characterize toughness of fiber reinforced composites are (i) the toughness thus measured can be more readily related to the fundamental fracture and crack propagation characteristics of the composites; and (ii) CMOD can be more readily related to crack width levels and, as a result, to levels of serviceability for the particular applications.

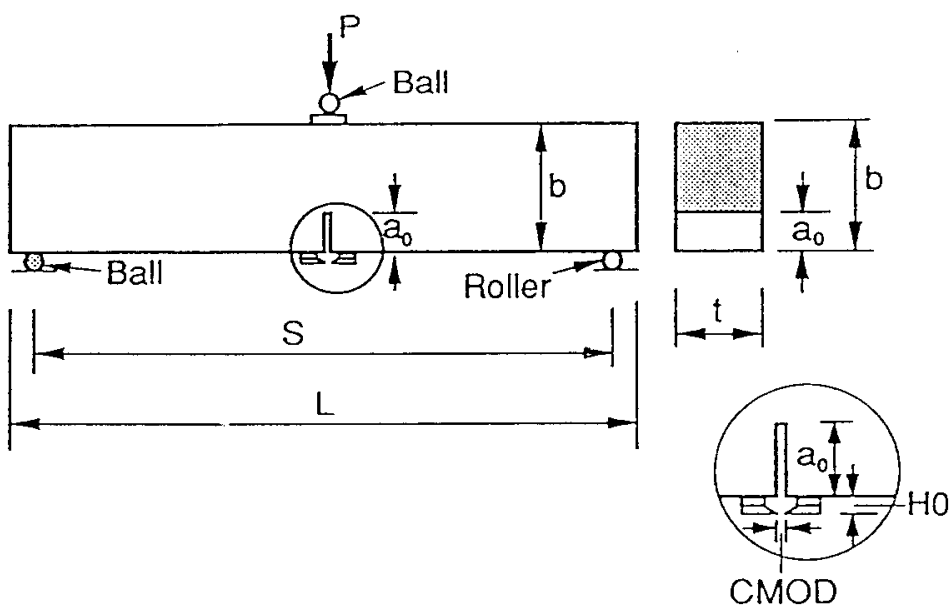

Fig. 15 Illustration of CMOD measurement using a notched beam 


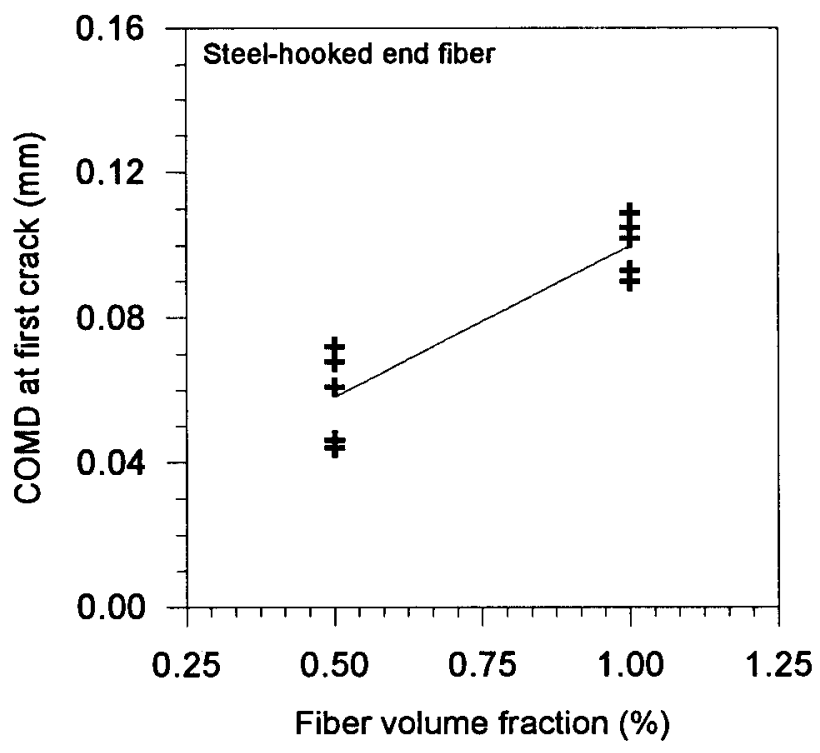

(a)

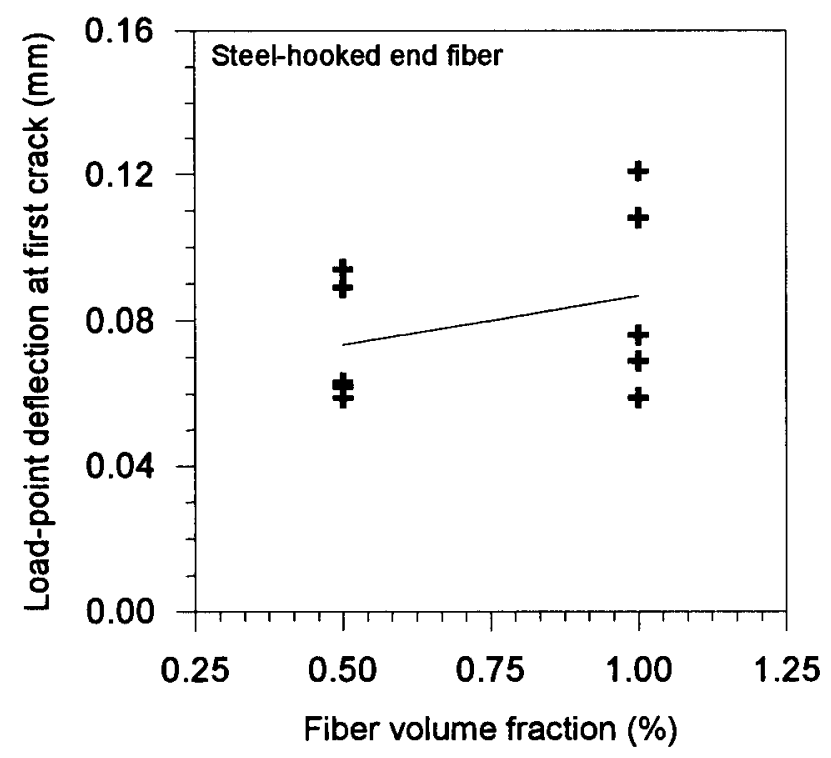

(b)

Fig. 16 Comparison of CMOD and deflection measurement[36] 
Baggott[44] has conducted the load-CMOD curves for steel fiber reinforced concrete with various fiber volume fractions and lengths and use these curves to calculate the fracture toughness. Beams tested under three-point bending had a span of $180 \mathrm{~mm}$, a depth of $50 \mathrm{~mm}$ and a width of $25 \mathrm{~mm}$. The notch length was 12.5 $\mathrm{mm}$. Baggott[44] also computed the J-integral based on his measurement. The result obtained is given in Table 1 . He reported that the CMOD value measured at peak load is primarily controlled by fiber length, rather than fiber volume fraction and matrix strength.

Table 1 Flexural strength and J-integral measured by Baggott[40]

\begin{tabular}{||c|c|c|c|c|c|c||}
\hline \multirow{2}{*}{$\begin{array}{c}\text { Mix } \\
\text { No." }\end{array}$} & \multicolumn{2}{|c|}{ Fiber (mm) } & $\begin{array}{c}\text { Fiber } \\
\text { volume } \\
\text { ratio } \\
(\%)\end{array}$ & $\begin{array}{c}\text { Stress at } \\
\text { proportional } \\
\text { limit (MPa) }\end{array}$ & $\begin{array}{c}\text { Flexural } \\
\text { strength } \\
\text { (MPa) }\end{array}$ & $\begin{array}{c}\text { J- } \\
\text { integral } \\
(\mathrm{kN} / \mathrm{m})\end{array}$ \\
\hline 1a & 10 & 0.15 & 1 & 4.1 & 4.9 & 0.39 \\
\hline 1b & 10 & 0.15 & 1 & 3.6 & 4.4 & 0.27 \\
\hline 2a & 10 & 0.15 & 5 & 13.3 & 18.6 & 1.5 \\
\hline 2b & 10 & 0.15 & 5 & 12.1 & 14.5 & 3.3 \\
\hline 3a & 10 & 0.15 & 10 & 29.3 & 39.8 & 5.4 \\
\hline 3b & 10 & 0.15 & 10 & 25.6 & 32.6 & 11.3 \\
\hline 4a & 10 & 0.15 & 15 & 37.9 & 49.4 & 13.1 \\
\hline 4b & 10 & 0.15 & 15 & 34.3 & 42.3 & 12.4 \\
\hline $5 a$ & 50 & 0.15 & 1 & 6.3 & 9.5 & 0.5 \\
\hline $5 b$ & 50 & 0.15 & 1 & 6.4 & 9.2 & 0.3 \\
\hline $6 a$ & 50 & 0.15 & 5 & 27.1 & 52.5 & 32.9 \\
\hline $6 b$ & 50 & 0.15 & 5 & 30.7 & 43.1 & 14.1 \\
\hline $7 a$ & 50 & 0.15 & 10 & 69.6 & 69.6 & 55.3 \\
\hline $7 b$ & 50 & 0.15 & 10 & 42.1 & 60.7 & 41.1 \\
\hline $8 a$ & 50 & 0.15 & 15 & 85.8 & 104.9 & 85.2 \\
\hline $8 b$ & 50 & 0.15 & 15 & 54.1 & 74.2 & 40.1 \\
\hline
\end{tabular}

* " $a$ " in mix \# indicates that the specimens were cured under autoclave temperature, whereas " $b$ " indicates that the specimens were cured under room temperature. 


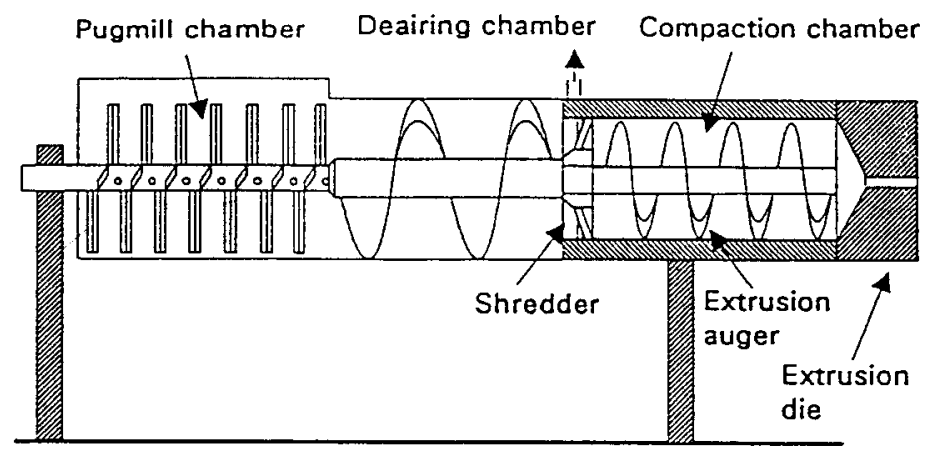

(a) Schematic of an auger type extruder

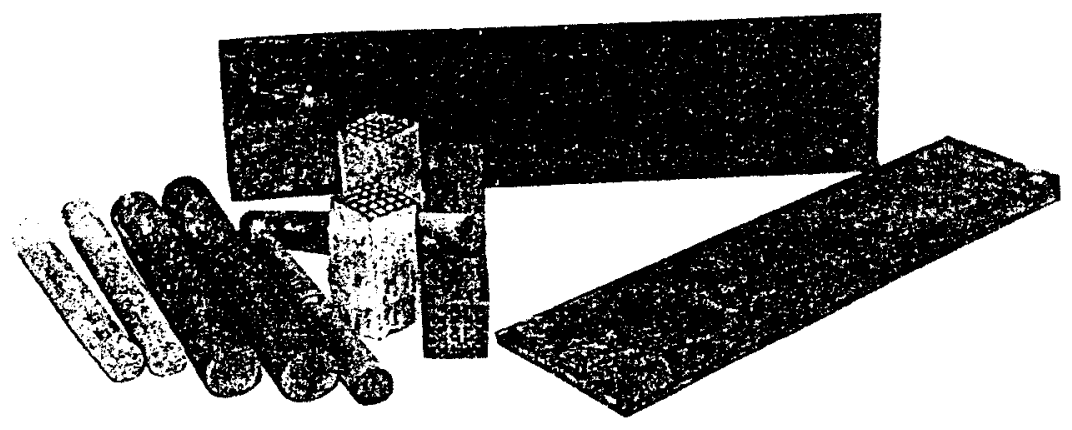

(b) Samples of extruded materials

Fig. 17 Schematic of an auger type extruder and sample of extruded materials[45] 


\section{Influence of processing technique}

High performance fiber reinforced cementitious composites can be fabricated by different process techniques, among which different kinds of premixing and shotcreting should be mentioned. The processing technique and the quality of curing influence considerably the toughening mechanisms. A technique recently developed is extrusion. The extrusion process is a plastic-forming technique that is commonly used in ceramic product manufacturing. In the extrusion process, a highly viscous, dough-like plastic mixture is forced through a shaped die. The schematic of an auger-type extruder in which the plasticized mix is forced through a shaped die by the rotation of an auger is illustrated in Fig. 17a, whereas some extruded samples of cementitious materials is shown in Fig. 17b. Shao[45] has recently conducted

\section{6:}
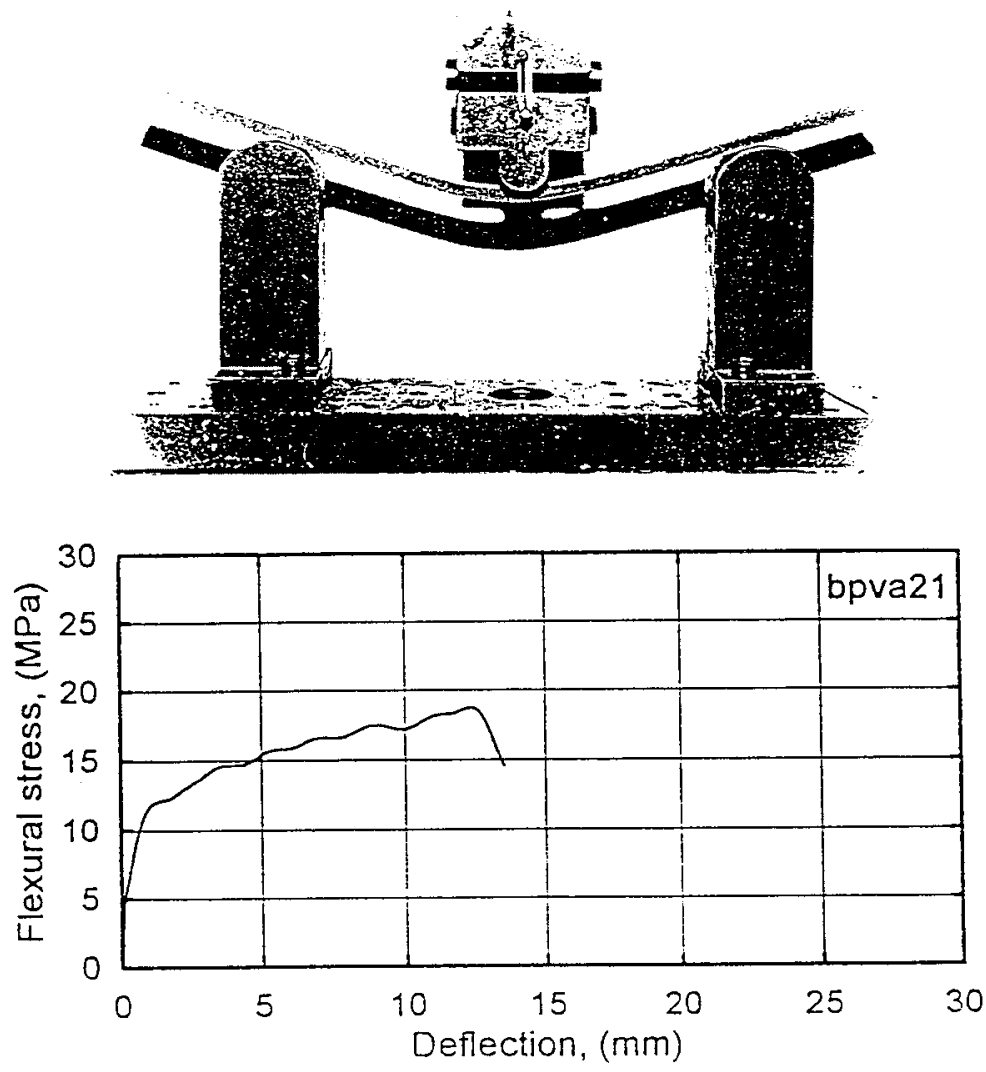

Fig. 18 Three-point bending test and the obtained flexural stress-deflection curve for an extruded composite with $2.2 \%$ pva fiber by volume[45] 
a series of tensile and flexural tests on the characterization of the extruded fiber reinforced composites. A typical load-deflection curve of an extruded discontinuous fiber reinforced composite thin plate is shown in Fig. 18. A pva fiber of the $6 \mathrm{~mm}$ length was used in the composite plate and the fiber volume fraction was $2.2 \%$. The extrusion technique fundamentally changes microstructure and mechanical property of cementitious composites even though only $2.2 \%$ of the fiber was used. This is characterized by the fact that (i) a pseudo strain hardening curve, instead of strainsoftening curve, resulting from multiple cracks was observed in Fig. 18, (ii) the flexural strength (point $\mathrm{A}$ ) is as high as about $12 \mathrm{MPa}$, compared to about $5 \mathrm{MPa}$ for conventional concrete, and (iii) ductility of the composite is greatly improved.

A similar observation was reported by Krenchel[46] using direct tensile specimens with $5.27 \%$ of discontinuous polypropylene fiber as shown in Fig. 19. He demonstrated that one can make high performance fiber reinforced cement (HPFRCC) composites with particle packing, multiple cracking and strain-hardening behavior at the same time. The strain-hardening response can be achieved using only limited amounts of cheaper types of synthetic fibers with 3-5\% of fiber volume fraction. Krenchel also tried to verify a criterion for multiple cracking, which was originally proposed by $\mathrm{Li}$ and $\mathrm{Wu}[47]$. He reported that this criterion was experimentally verified to some extend. But some specimens showed multiple cracking even though the criterion is violated.

ASTM C1018 is obviously incapable of characterizing the above observed pseudo strain hardening response for high performance fiber reinforced composites. In order to describe this pseudo hardening response, one first needs to understand toughening mechanisms resulting in this response. Shao[45] has conducted a microscopic study to understand these mechanisms.

Strong interface bond is a major contribution to the strain hardening type of response. The interface bond between fiber and matrix was examined at a larger magnification and is shown in Fig. 20[45]. A matrix crack passed through a fiber, causing some debonding at the interface. Instead of propagating along the interface, the interface crack kinked away from the interface both into the matrix, causing matrix cracking in the interface neighborhood, and into the fiber, causing the fiber to break inside the debonded zone. The rest of the interface maintained a good bond condition. The fiber preferably broke inside the small debonded zone, rather than to stretch further away along the fiber to debond the rest of the interface. Since the fiber-matrix interface is much stronger in an extruded composite, fiber pull-out is seldom observed.

Fiber alignment in the extruded composite is an another reason accounting for the strain hardening post-peak response. Fig. 21 shows the distribution and orientation of the short fibers in the extruded composite[45]. It is observed that the extrusion process is capable of reorienting short fibers basically in the extrusion flow direction. make the fibers more or less alignment compared to randomly distribution. This increases the efficiency of the fibers bridging.

Based on these observations, one can concluded that strong the fiber matrix interface and fiber orientation in desired direction are primary contributions to pseudo strain hardening response of the composites. These two factors assure the formation of multiple cracks in an extruded composite. This multiple cracking pattern at a tensile strain of $1.36 \%$ is illustrated in Fig. 22 for an extruded composite[45]. The distributed crack bands consume great amount of strain energy 


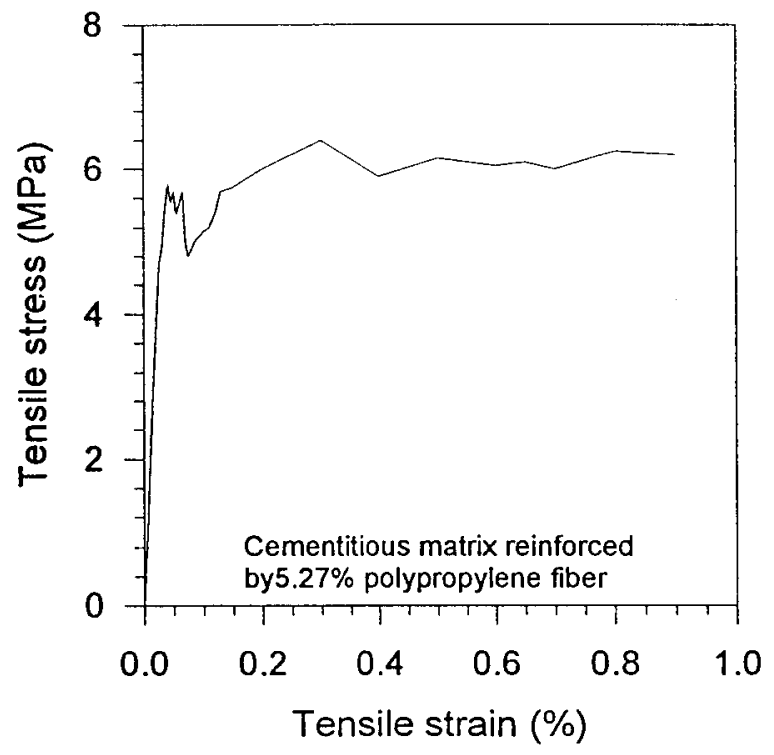

Fig. 19 Tensile stress-strain relationship for a cementitious matrix reinforced by $5.27 \%$ of polypropylene fiber[46]

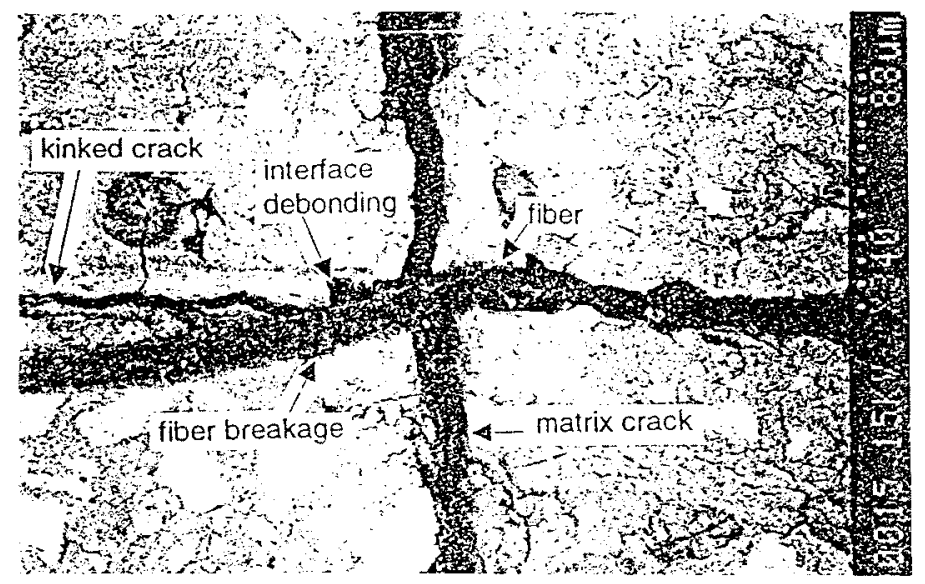

Fig. 20 Strong interface bond leads to interface crack away from the interface[45] 


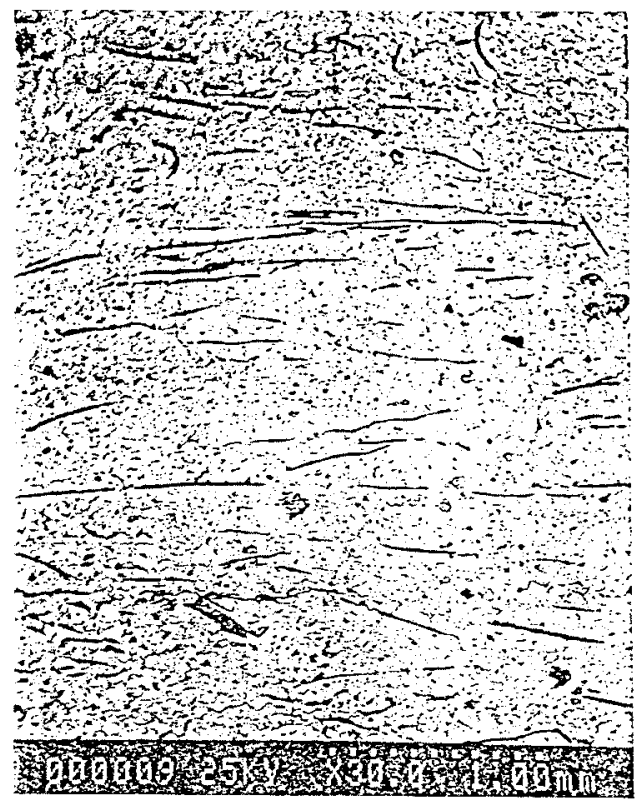

Fig. 21 Fiber orientation and distribution in an extruded composite with $2.2 \%$ pva fiber[45]

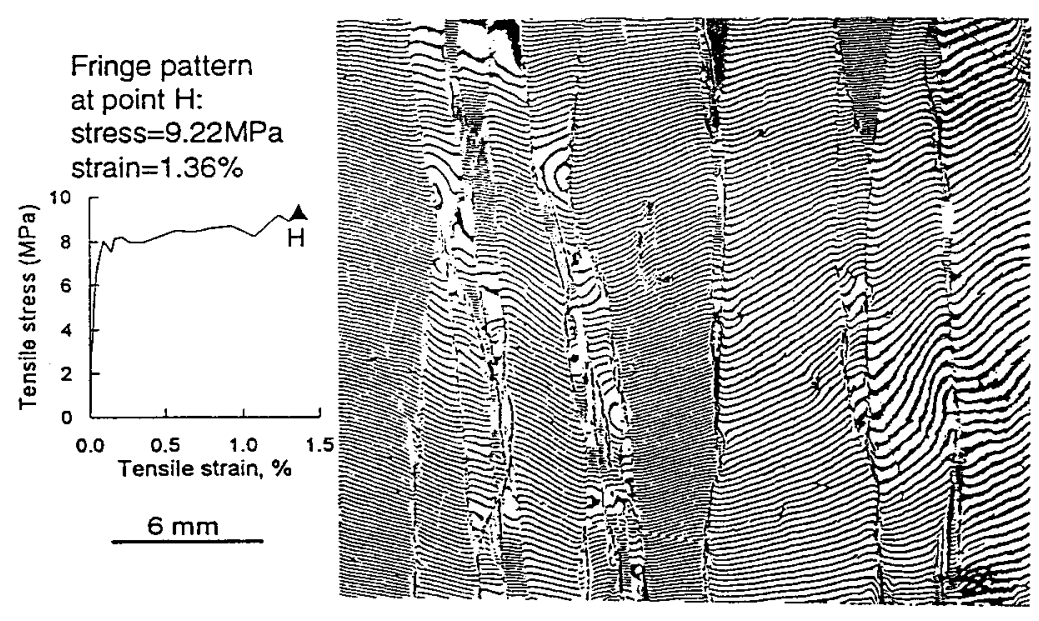

Fig. 22 Moire fringe patterns representing deformation and fracture of an extruded composite with $4.2 \%$ of fiber[45] 
and prevent the composite failure from strain localization.

\section{Design compressive strain softening curve}

The use of fibers in cementitious materials improves the softening part of stressstrain curve. For the purpose of design, Taerwe and Van Gysel[48] has recently proposed the following compressive softening stress-strain curve for high strength concrete by taking influence of steel fibers into account,

$$
\frac{\sigma_{c}(n)}{f_{c}}=\frac{1}{1+\left[(n-1) /\left(n_{2}-1\right)\right]^{2}}, \quad n=\frac{\varepsilon_{c}}{\varepsilon_{c 1}}
$$

where $\sigma_{c}$ is the post-peak compressive stress, $\mathrm{f}_{\mathrm{c}}$ is the compressive strength of concrete. The value of $n_{2}$ is the parameter depending $\mathrm{cn}$ the reinforcing index, RI $=\mathrm{V}_{\mathrm{f}} \mathrm{L} / \mathrm{d}$, and is given below,

$$
n_{2}=\left[1.1035-0.4212\left(\frac{f_{c}}{50}\right)\right] R I-0.8037\left(\frac{f_{c}}{50}\right)+2.8797
$$

Since $\mathrm{RI}$ is a function of the fiber volume fraction, $\mathrm{V}_{\mathrm{f}}$, and the aspect ratio, $\mathrm{L} / \mathrm{d}, \mathrm{RI}$ can also be related to the toughness index.

The softening part of stress-strain curves specified by Eqs. (14) and (15) are plotted in Fig. 23 (with $f_{c}=80 \mathrm{MPa}$ ) for values of $R I=0.3$ and 0.6 , respectively.

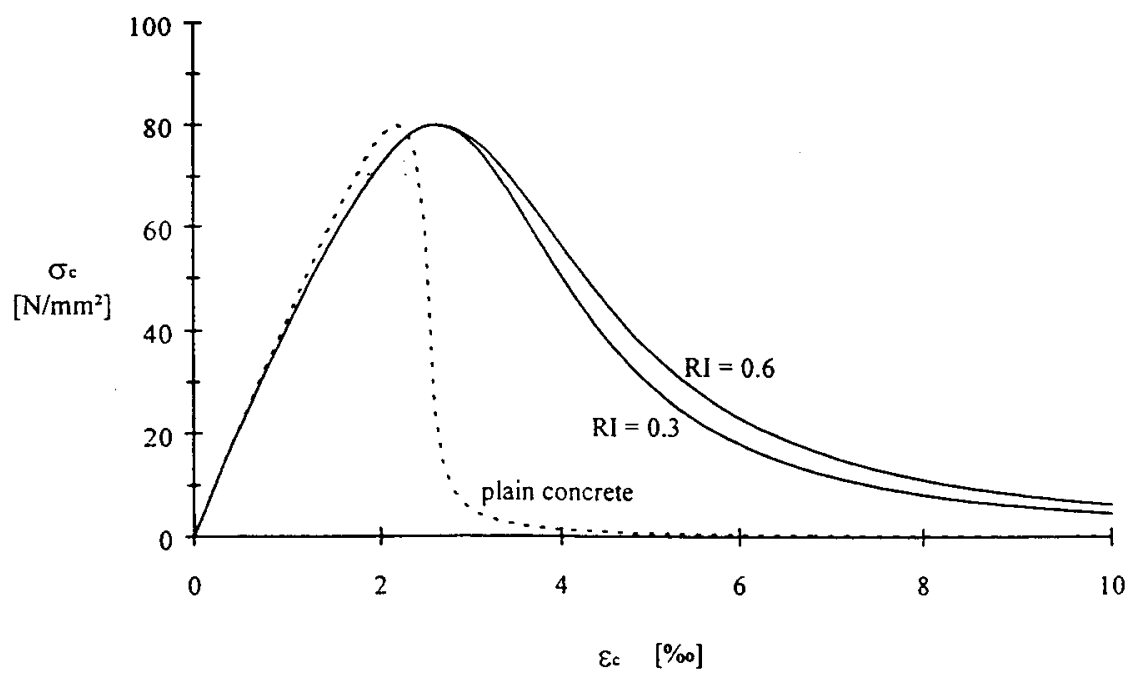

Fig. 23 Proposed design compressive stress-strain curve[48] 


\section{The effect of loading rate}

Eibl[49] has studied the effect of loading rate on stress-strain response of fiber reinforced cementitious composites. He tested a series of cylindrical cores under uniaxial tension and uniaxial compression, respectively. These cores were drilled horizontally and vertically, respectively, from the pre-cast fiber reinforced concrete slabs of $1060 \times 1060 \times 200 \mathrm{~mm}$. The fiber content was $1.2 \%$ by volume for the fiber reinforced concrete. The cores under uniaxial tension were $75 \mathrm{~mm}$ in diameter and $100 \mathrm{~mm}$ long, with a circular notch of $8 \mathrm{~mm}$ depth. The strain rates were $1 \mathrm{x}$ $10^{-6}$ per second for static loading, 0.013 per second for dynamic loading, and 2.4 per second for impact loading, respectively. On the other hand, the cores subjected to uniaxial compression were $100 \mathrm{~mm}$ in diameter and $250 \mathrm{~mm}$ long. The strain rates were $2.4 \times 10^{-5}$ per second for static loading, 0.079 per second for dynamic loading, and 12.2 per second for impact loading, respectively.

The obtained tensile stress-extension curves for the composite with a Dramix steel fiber of $600 \mathrm{~mm}$ long and $0.8 \mathrm{~mm}$ diameter, hooked end smooth wire, are shown in Fig. 24a. As seen in the figure, the slope of the stress-extension curves clearly increases with increasing strain rate. This is probably due to limited crack velocity as a consequence of fiber induced crack arrest. The influence of notch may increase this effect.

The tensile stress-extension curves of the plain concrete, loaded at the same rates with the fiber reinforced concrete, are also shown in Fig. 24b for comparison. The fiber reinforced concrete can resist much higher post-peak stress than the plain concrete.

The influence of the strain rate on peak-stresses for both the tension and compression are shown in Figs. 25a and b, respectively. It was observed that the peak-stresses increase with increasing strain rate.

\section{Summary}

This chapter summarizes some state-of-the-art basic understanding on fiber reinforced concrete. Toughening mechanisms in fiber reinforced cementitious composites have been summarized based on several experimental observations.

The use of suitable amount of fibers can hinder or offset the strain localization which usually controls fracture process of cementitious materials. The effect of fiber on hindering the strain localization primarily depends on factors such as the fiber-matrix interface as well as volume, length and orientation of fibers. It is no doubt that some important experimental findings and interesting aspects of toughening mechanisms have been only briefly discussed or even omitted here. A series of theoretical models for describing these factors have been briefly discussed. Some current methods for characterizing toughness of fiber reinforced cementitious composites have been reviewed. The use of fibers may fundamentally change mechanical property of cementitious materials. To achieve this goal, more studies are certainly needed in this area. 


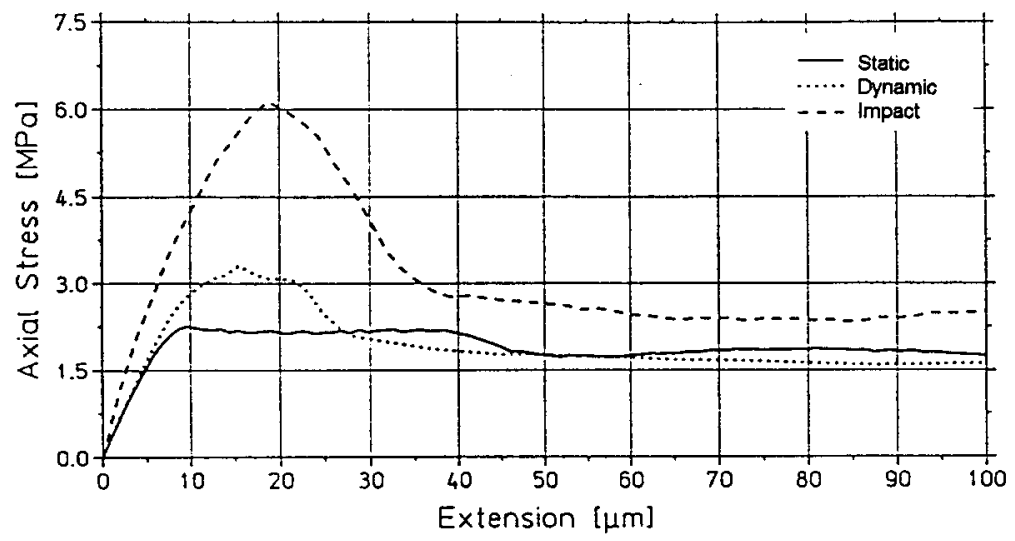

(a) Dramix fiber reinforced concrete mix

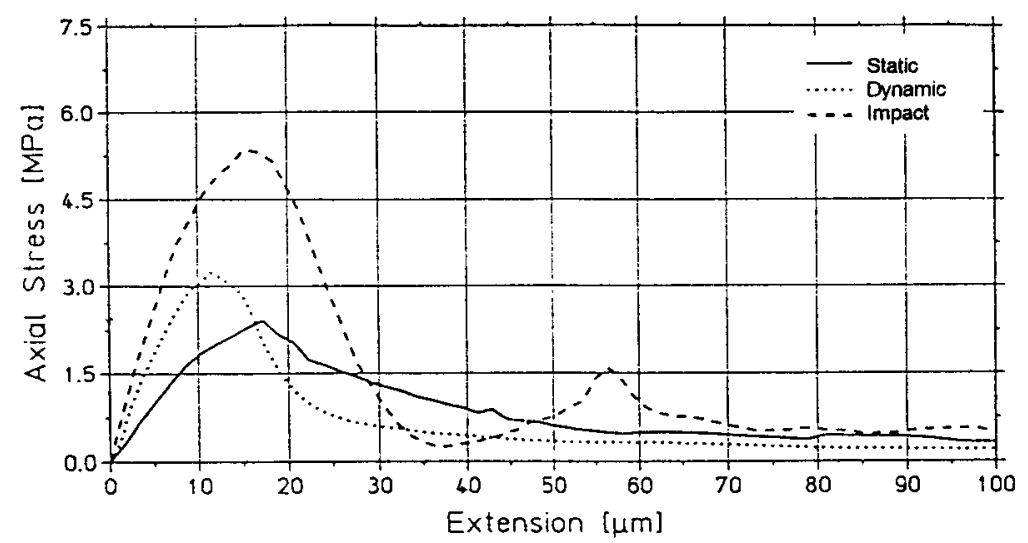

(b) Plain concrete mix

Fig. 24 Effect of loading rate on tensile stress-extension response[49] 


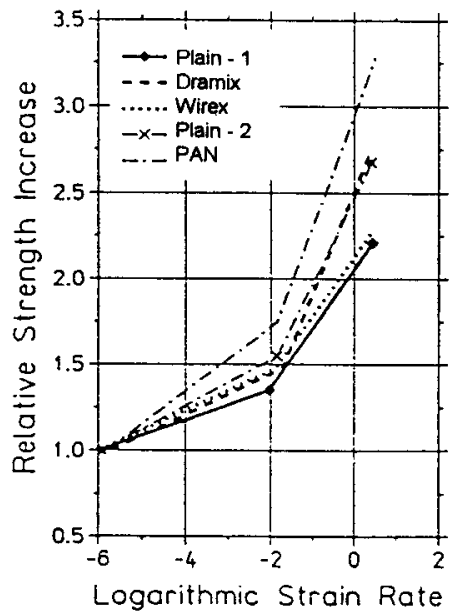

(a) Tensile loading

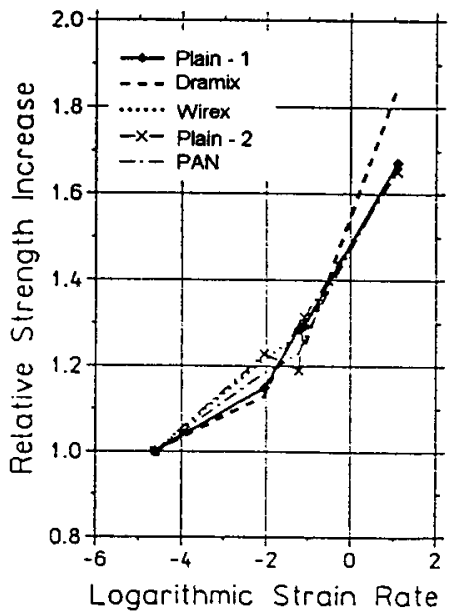

(b) Compressive loading

Fig. 25 Effect of loading rate on peak-stress of fiber reinforced cement composites[49] 


\section{References}

1. Li, Z., Kulkarni, S. M., and Shah, S. P. (1993) New test method for obtaining softening response of unnotched concrete specimen under uniaxial tension. Experimental Mechanics, Vol. 33, pp. 181-188.

2. Landis, E. N., and Shah, S. P. (1993) Recovery of microcrack parameters in mortar using quantitative acoustic emission. Journal of Nondestructive Evaluation, Vol. 12, No. 4, pp. 219-232.

3. Shah, S.P., and Ouyang, C. (1991) Mechanical behavior of fiber-reinforced cement-based composites. Journal of the American Ceramic Society, Vol. 74, No. 11, pp. 2727-2737 \& 2947-2953.

4. Betterman, L.R., Ouyang, C. and Shah, S.P. (1995) Fiber-matrix interaction in microfiber reinforced mortar. Journal of Advanced Cement-Based Materials, Vol. 2, pp.53-61.

5. Stang, H., Mobasher, B., and Shah, S.P. (1990) Quantitative damage characterization in polypropylene fiber reinforced Concrete. Cement and Concrete Research, Vol. 20, pp. 540-558.

6. Mobasher, B., Castro-Montero, A, and Shah, S.P. (1990) A study of fracture in fiber reinforced cement-based composites using laser holographic interferometry. Experimental Mechanics, Vol. 30, pp. 286-294.

7. Brandt, A. M., and Glincki, M. A. (1992) Flexural behavior of concrete elements reinforced with carbon fibers. High Performance Fiber Reinforced Cement Composites, (eds. H. W. Reinhardt, and A.E. Naaman), E \& FN Spon, London, pp. 288-299.

8. Shao, Y., Li, Z. and Shah, S.P. (1993) Matrix cracking and interface debonding in fiber-reinforced cement-matrix composites. Journal of Advanced Cement Based Materials, Vol. 1, No. 2, pp. 55-67.

9. Li, V.C. (1995) Advances in strain-hardening cement based composites. Proceedings of engineering foundation conference on advances in cement and concrete (eds. M. Grutzeck and S. Sarkar), to be published by ASCE.

10. Li, V.C., Hashida, T. (1993) Engineering ductile fracture in brittle matrix composites. Journal of Materials Science Letters, Vol. 12, pp. 898-901.

11. Maalej, M., Hashida, T., and Li, V. C. (1995) Effect of fiber volume fraction on the off-crack-plane fracture energy in strain-hardening engineered cementitious composites. Journal of American Ceramic Society, in press.

12. Potrzebowski, J. (1988) Debonding process between steel fiber and cement matrix. Proceedings of international symposium on brittle matrix composites 2, Elsevier Applied Science, pp. 352-361.

13. Bartos, P., (1981) Review paper: bond in fiber reinforced cements and concretes. The International Journal of Cement Composites and Lightweight Concrete, Vol. 3, pp. 159-177.

14. Gray, R. J. (1984) Analysis of the effect of embedded fibre length on fibre debonding and pull-out from an elastic matrix, part I, review of theory. Journal of Materials Science, Vol. 19, pp. 861-870.

15. Lawrence, P. (1972) Some theoretical considerations of fibre pull-out from an elastic matrix. Journal of Materials Science, Vol. 7, pp. 1-6. 
16. Gopalaratnam, V. S., and Shah, S. P. (1987) Tensile failure of steel-fiberreinforced mortar. Journal of Engineering Mechanics Division, ASCE, Vol. 113, No. 5, pp. 635-652.

17. Stang, H., Li, Z., and Shah, S. P. (1990) Pullout problem: stress versus fracture mechanical approach. Journal of Engineering Mechanics, Vol. 116, No. 10, pp. 2136-2150.

18. Li, Z., Mobasher, B., and Shah, S. P. (1991) Characterization of interfacial properties in fiber reinforced cementitious composites. Journal of the American Ceramic Society, Vol. 74, No. 9, pp. 2156-2164.

19. Ouyang, C., Pacios, A., and Shah, S. P. (1994) Pullout of inclined fibers from cementitious matrix. Journal of Engineering Mechanics, ASCE, Vol. 120, No.12, pp. 2641-2659.

20. Somayaji, S., and Shah, S. P. (1981) Bond stress versus slip relationship and cracking response of tension members. ACI Journal, Proceedings, Vol. 78, No. 3, pp. 217-225.

21. Morton, J., and Groves, G. W. (1974) The cracking of composites consisting of discontinuous ductile fibers in a brittle matrix - effect of fiber orientation. Journal of Materials Science, Vol. 9, pp. 1439-1445.

22. Brandt, A. M. (1985) On the optimal direction of short metal fibers in brittle matrix composites. Journal of Materials Science, Vol. 20, pp. 3835-3841.

23. Li, V. C., Wang, Y., and Backer, S. (1990) Effect of inclining angle, bundling, and surface treatment on synthetic fiber pull-out from a cement matrix. Composites, Vol. 21, No. 2, pp. 132-140.

24. Pacios, A., Ouyang, C., and Shah, S. P. (1995) Rate effect on interfacial response between fibers and matrix. Materials and Structures, Vol. 28, pp. 8391.

25. Park, S.B., Lee, B.I., and Lim, Y.S. (1991) Experimental study on the engineering properties of carbon fiber reinforced cement composites. Cement and Concrete Research, Vol. 21, pp. 589-600.

26. Mihashi, H., Kirikoshi, K., and Nomura, N. (1992) Strength properties of FRC on the basis of fracture mechanisms. High performance fiber reinforced cement composites, (eds. H.W. Reinhardt and A.E Naaman), E \& FN Spon, London, pp. 313-324.

27. Mobasher, B., Ouyang, C., and Shah, S. P. (1991) Modeling of fiber toughening in cementitious materials using an $R$-curve approach. International Journal of Fracture, Vol. 50, pp. 199-219.

28. Ouyang, C., and Shah, S. P. (1992) Toughening of high strength cementitious matrix reinforced by discontinuous short fibers. Cement and Concrete Research, Vol. 22, pp. 1201-1215.

29. Mobasher, B., Li, C.Y., and Arino, A. (1995) Experimental R-curves for assessment of toughening in fiber reinforced cementitious composites. $A C I$ Special Publication, in press.

30. Mobasher, B., Li, C.Y. (1995) Mechanical properties of hybrid cement based composites. ACI Materials Journal, in press. 
31. Yang, C. C., Mura, T., and Shah, S. P. (1991) Micromechanical theory and uniaxial tensile tests of fiber reinforced cement composites. Journal of Materials Research, Vol.6, No. 11, pp. 2463-2473.

32. Li, S.H., Shah, S.P., Li, Z. and Mura, T. (1993) Micromechanical analysis of multiple fracture and evaluation of debonding behavior for fibre-reinforced composites. International Journal of Solids and Structures, Vol. 30, No. 11, pp. 1429-1459.

33. Brandt, A.M., and Stroeven, P. (1992) Fracture energy in notched steel fiber reinforced concrete beams. Proceedings of international symposium "Brittle Matrix Composites 3", Elsevier Applied Science, London and New York, pp. 72-82.

34. ASTM C 1018-89 Standard test method for flexural toughness and first-crack strength of fiber-reinforced concrete (using beam with third-point loading). 1984 Book of ASTM Standards, Part 04.02, Philadelphia, pp. 499-505.

35. Standard SF4, (1983) Method of test for flexural toughness of fiber reinforced concrete. JCI Standards for test methods of fiber reinforced concrete. Japan Concrete Institute, pp. 45-54.

36. Gopalaratnam, V.S., Shah, S.P., Batson, G.B., Criswell, M.E., Ramakrishnan, V., and Wecharatana, M. (1991) Fracture toughness of fiber reinforced concrete. ACI Materials Journal, Vol. 88, No. 4, pp. 339-353.

37. ACI Committee 544, (1988) Measurement of properties of fiber reinforced concrete. ACI Materials Journal, Vol. 85, No. 6, pp. 583-593.

38. Mindess, S., Chen, L., and Morgan, D.R. (1994) Determination of the firstcrack strength and flexural toughness of steel fiber-reinforced concrete. Advanced Cement Based Materials, Vol.1, No.5, pp.201-208.

39. Contribution of Lambrechts, A. (1995) High strength hooked end steelwire fibers for high strength concrete.

40. Contribution of Brandt, A.M. (1995) Toughness characterization and toughness mechanisms.

41. Brandt, A.M. (1995) Cement-based composites: materials, mechanical properties and performance. E \& FN Spon/Chapman \& Hall, London, p. 470.

42. Kucharska, L. and Brandt, A.M. (1995) High performance cement mortars with and without silica fume reinforced with low amount of carbon fibers. 5th CANMET/ACI international conference on use of fly ash, silica fume, slag and natural pozzolans in concrete, Milwaukee, June 4-9, in print.

43. Contribution of Glinicki, M. A. (1995) Energy absorption capacity of highperformance GFRC composites.

44. Contribution of Baggott, R., (1995).

45. Shao, Y. (1995) Characterization of high performance fiber-reinforced cement composites. Ph. D Dissertation, Northwestern University, $146 \mathrm{pp}$.

46. Contribution of Krenchel, H. (1995) Microfiller material for high performance fiber-reinforced cement composites.

47. Li, V.C., and Wu, H.-C. (1992) Conditions for pseudo strain-hardening in fiber reinforced brittle matrix. Applied Mechanics Review, Vol. 45, No. 8. 
48. Contribution of Taerwe, L. and Van Gysel, A (1995) Influence of the toughness effect of steel fibers on the design stress-strain curve for high strength concrete.

49. Contribution of Eibl, J. (1995) Strain rate effects including impact loading. 